\title{
Potential Implications of Citrulline and Quercetin on Gut Functioning of Monogastric Animals and Humans: A Comprehensive Review
}

\author{
Victoria Anthony Uyanga ${ }^{1,2,+} \mathbb{D}$, Felix Kwame Amevor ${ }^{2,3,+} \mathbb{D}$, Min Liu ${ }^{1}$, Zhifu Cui ${ }^{3}$, Xiaoling Zhao ${ }^{3, *(D)}$ \\ and Hai Lin 1 ,* \\ 1 Shandong Provincial Key Laboratory of Animal Biotechnology and Disease Control, Department of Animal \\ Science, College of Animal Science and Veterinary Medicine, Shandong Agricultural University, \\ Tai'an City 271018, China; uyangava@sdau.edu.cn (V.A.U.); lmliumin1991@sina.com (M.L.) \\ 2 Organization of African Academic Doctors (OAAD), Off Kamiti Road, Nairobi P.O. Box 25305-00100, Kenya; \\ amevorfelix@gmail.com \\ 3 Farm Animal Genetic Resources Exploration and Innovation Key Laboratory of Sichuan Province, Sichuan \\ Agricultural University, Chengdu 611130, China; 2018102013@stu.sicau.edu.cn \\ * Correspondence: zhaoxiaoling@sicau.edu.cn (X.Z.); hailin@sdau.edu.cn (H.L.); Tel.: +86-028-8629-1010 (X.Z.); \\ +86-538-824-9203 (H.L.); Fax: +86-028-8629-1010 (X.Z.); +86-538-824-1419 (H.L.) \\ + These authors contributed equally to this work.
}

Citation: Uyanga, V.A.; Amevor, F.K.; Liu, M.; Cui, Z.; Zhao, X.; Lin, H. Potential Implications of Citrulline and Quercetin on Gut Functioning of Monogastric Animals and Humans: A Comprehensive Review. Nutrients 2021, 13, 3782. https://doi.org/ $10.3390 /$ nu13113782

Academic Editor: Henry J. Thompson

Received: 22 July 2021

Accepted: 19 October 2021

Published: 25 October 202

Publisher's Note: MDPI stays neutra with regard to jurisdictional claims in published maps and institutional affiliations.

Copyright: (c) 2021 by the authors. Licensee MDPI, Basel, Switzerland. This article is an open access article distributed under the terms and conditions of the Creative Commons Attribution (CC BY) license (https:// creativecommons.org/licenses/by/ $4.0 /)$.
Abstract: The importance of gut health in animal welfare and wellbeing is undisputable. The intestinal microbiota plays an essential role in the metabolic, nutritional, physiological, and immunological processes of animals. Therefore, the rapid development of dietary supplements to improve gut functions and homeostasis is imminent. Recent studies have uncovered the beneficial effects of dietary supplements on the immune response, microbiota, gut homeostasis, and intestinal health. The application of citrulline (a functional gut biomarker) and quercetin (a known potent flavonoid) to promote gut functions has gained considerable interest as both bioactive substances possess anti-inflammatory, anti-oxidative, and immunomodulatory properties. Research has demonstrated that both citrulline and quercetin can mediate gut activities by combating disruptions to the intestinal integrity and alterations to the gut microbiota. In addition, citrulline and quercetin play crucial roles in maintaining intestinal immune tolerance and gut health. However, the synergistic benefits which these dietary supplements (citrulline and quercetin) may afford to simultaneously promote gut functions remain to be explored. Therefore, this review summarizes the modulatory effects of citrulline and quercetin on the intestinal integrity and gut microbiota, and further expounds on their potential synergistic roles to attenuate intestinal inflammation and promote gut health.

Keywords: tight junctions; flavonoids; intestinal immunity; metabolism; nitric oxide; microbiota

\section{Introduction}

Nutrition directly influences gut microbial composition and functions, with significant impacts on host health [1]. The microbiota, dietary factors, and their metabolites are in close contact to the gut epithelium, forming a thin cell-layer that separates the constituents of the host from its external setting [2,3]. Generally, the tight junction proteins (including claudins, zona occludin-1, and occludin), act to maintain the gut barrier integrity, in turn promoting epithelial cell barrier functions [4]. It is obvious that during gut disorders, the functionality of the tight junction proteins declines, which would lead to the gut becoming permeable to toxic substances, causing severe systemic inflammatory responses [3]. Therefore, changes in the gut microbiota may produce disorders including cancer, leaky guts, diabetes, obesity, and neurological disorders [5]. Inflammatory bowel disease (IBD) occurs due to dysregulation in the immune system, leading to intestinal inflammation and microbial dysbiosis [3]. Studies have reported on the roles of dietary supplements, and 
their effects on the microbiota and gut metabolites during physiological processes such as immunity, metabolism, and neurological and nutritional homeostasis [6,7]. Moreover, nutritional strategies intended at repairing intestinal mucosal damage also tend to elicit beneficial effects on the microbiota, immune system, digestive physiology, and inflammatory response [5]. Metagenomic analyses have revealed amino acid metabolism and transport as an integral metabolic activity of the intestinal microbiota [8]. This suggests that the positive benefits of nutritional intervention would not only modulate gut function, but ameliorate the adverse impacts of gut inflammation and dysfunction under various pathophysiological conditions.

Citrulline (CIT) (commonly found as L-citrulline), a non-essential amino acid with unique metabolic properties, has emerged as a promising pharmaconutrient [9]. Citrulline has been implicated in several regulatory roles, including gut modulation, antioxidative and anti-inflammatory effects, protein synthesis, nitrogen homeostasis, blood pressure regulation, renal function, cardiac function, skeletal muscle function, vascular health, lipid and energy metabolism, arginine production, and thermoregulation [10-13]. Several studies have revealed the efficacy of citrulline in serving as an arginine precursor and in nitric oxide production, especially in cases of acute or chronic inflammation [14,15]. Relatively few studies are available on citrulline in animals; however, it is subtly gaining research interest due to its unique metabolism. Citrulline is a functional marker of gut barrier dysfunction [16], and has been associated with various intestinal diseases, including short bowel syndrome [17,18], gastric ulcers [19], and necrotizing enterocolitis [20]. Recently, flavonoids, a group of natural compounds abundant in plants sources, such as bark, roots, stems, fruits, vegetables, bulbs, wine, and tea, have gained widespread attention for their therapeutic effects such as anti-oxidative, anti-inflammatory, cardioprotective, anti-estrogenic, neuroprotective, and chemoprotective roles [21,22]. Quercetin is the primary polyphenolic flavonoid present in foods and it has been studied for its numerous beneficial properties including enhancing gut microbial composition, functions, and disease prevention [2].

This review aims to expound our understanding on the functional roles of citrulline and quercetin on gut health, their interaction with the gut microbiota, and their actions to establish gut immune homeostasis. We further discuss the potential synergistic roles for which they can be utilized, as this currently exists as a huge knowledge gap. An understanding of the roles exerted by citrulline and quercetin to mediate gut functions either individually or when co-utilized would expand the knowledge base for the application of these dietary supplements in health and disease conditions.

\section{Overview on Citrulline and Quercetin}

L-citrulline, $\mathrm{C}_{6} \mathrm{H}_{13} \mathrm{O}_{3} \mathrm{~N}_{3}$, is a non-protein, neutral, non-essential, alpha-amino acid that also serves as an important metabolite of the urea cycle [23]. L-citrulline has an alphastructured chemical configuration (Figure 1), with a molecular mass of 175.19 Daltons, and high solubility in water [24]. As a non-protein monomer, citrulline does not undergo protein synthesis but rather can occur from post-translational modifications and products of the Golgi body [24]. Naturally, citrulline is largely concentrated in watermelon (Citrullus lanatus (Thunb.) Matsum. \& Nakai Cucurbitaceae) fruits, but although present in vegetative tissues (such as stems, seedlings, and leaves) and root, citrulline is confirmed to progressively accumulate majorly in the fruit flesh and rind tissues of watermelons [25]. It can range from 1.6 to $3.5 \mathrm{~g} / \mathrm{kg}$ L-citrulline in freshly obtained watermelon [11].

Quercetin (3, $3^{\prime}, 4^{\prime}, 5,7$-pentahydroxyflavanone) exists in several forms as quercetin glycoside, quercetin sulfate, quercetin glucuronide, and methylated quercetin [26]. Biochemically, quercetin is an aglycone that contains no sugar molecule and shows partial solubility and insolubility in hot water and cold water, respectively. It is, however, completely soluble in lipids and alcohol [26,27]. The formation of quercetin glycoside is through the attachment of quercetin to a sugar group (Figure 2). The resulting structure after the successful attachment has a changed biochemical structure which allows for easy solubility, absorption, and metabolism [27]. Research has recently focused on the application of 
quercetin to promote the composition of the gut microflora, facilitating immunoregulation and gut functions [28]. Quercetin can be extracted from various plants including Moringa oleifera, Sophora Japonica L., berries, apples, and onions [28,29]. Quercetin exhibits unique biological characteristics including antibiotic, anti-oxidative, anti-inflammatory, immunomodulatory, and anti-fibrotic effects $[26,30,31]$. As an important dietary antioxidant, quercetin scavenges reactive oxygen species (ROS) and reactive nitrogen species (RNS), inhibits lipid oxidation, and chelates iron, protecting cells against oxidative damages [32].<smiles>NC(=O)NCCC[C@H](N)C(=O)O</smiles>

Figure 1. Chemical structure of L-citrulline.<smiles>O=c1c(O)c(-c2ccc(O)c(O)c2)oc2cc(O)cc(O)c12</smiles>

Figure 2. Chemical structure of quercetin.

\section{Metabolism of Citrulline and Quercetin}

\subsection{Metabolism of L-Citrulline}

L-citrulline is essentially biosynthesized through the nitric oxide and the urea cycle, with the urea cycle accounting for $\sim 90 \%$ production, and the nitric oxide cycle producing $\sim 10 \%$ of L-citrulline $[24,33]$. Citrulline can be directly formed from L-arginine via the activity of nitric oxide synthase (NOS) enzymes, which exist as constitutive (cNOS) and inducible (iNOS) isoforms [34]. The cNOS is calcium/calmodulin-dependent and found in endothelial cells (eNOS) and neuronal cells (nNOS), whereas, the iNOS, which is calcium/calmodulin-independent, is triggered during inflammatory conditions by bacterial toxins or cytokines in many cell types, including macrophages, neutrophils, and endothelial cells [35].

Within the small intestine, citrulline is synthesized from glutamine by the enterocytes, releasing citrulline into blood circulation for metabolism into arginine by the kidneys [36]. The small intestine has been established as the major site for citrulline production due to the abundance of citrulline synthesizing enzyme (pyrroline-5-carboxylate synthase, P5CS) and the lower activity of citrulline catabolizing enzymes, such as argininosuccinate synthase and argininosuccinate lyase $[9,37]$. In citrulline synthesis from glutamine, intestinal catabolism plays a significant role in humans, pigs, and rats, since the enzyme intermediate P5CS, is almost exclusively located in the intestinal mucosa [38,39]. L-citrulline synthesis from L-glutamine occurs through a transaminase reaction in the enterocytes [11]. The citrulline produced from the enterocytes is absorbed by the kidney (proximal tubular cells), and the enzymatic actions of arginosuccinate synthase and arginosuccinate lyase rapidly convert the L-citrulline formed into L-arginine [38] (Figure 3). This reaction pathway provides $\sim 50 \%$ of daily arginine needs in young mammals [39], and meets the entire arginine requirement in healthy adult mammals [40]. Using irinotecan-treated rats, mRNA expression analysis revealed that P5CS, glutaminase, ornithine aminotransferase, and ornithine 
carbamoyltransferase enzymes, which are responsible for citrulline synthesis from glutamine in enterocytes, were downregulated, whereas arginase 2 and proline dehydrogenase, responsible for citrulline synthesis from proline or arginine, were unaffected [41].

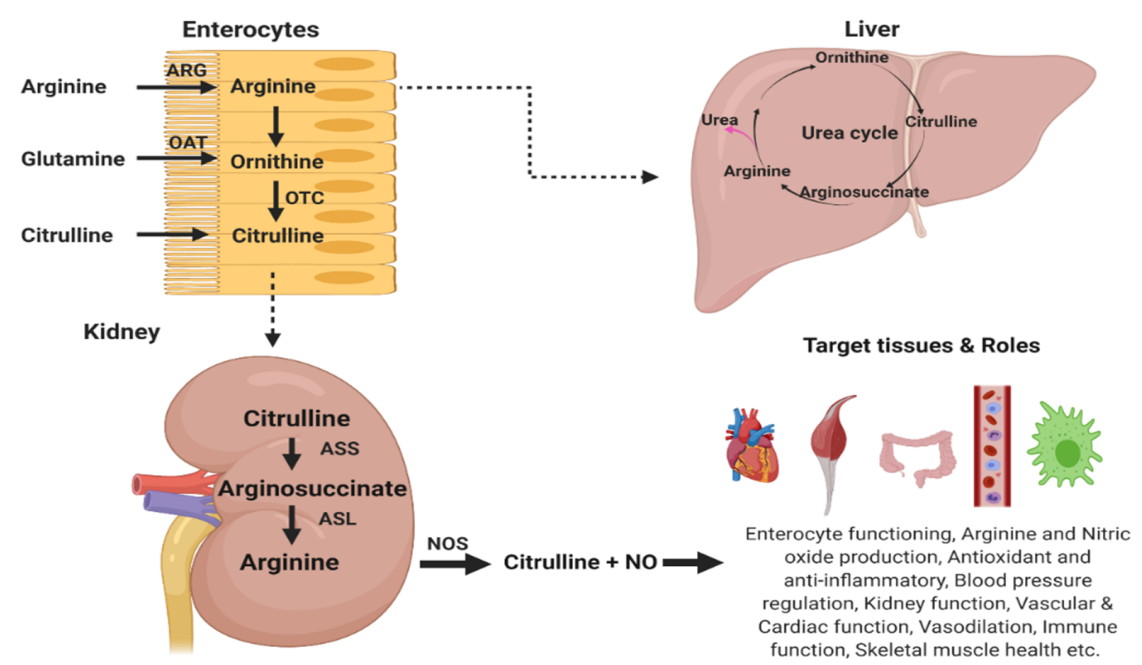

Figure 3. Overview of citrulline metabolism and related amino acids. ARG, arginase; OAT, ornithine aminotransferase; OCT, ornithine carbamoyltransferase; ASS, argininosuccinate synthetase; ASL, argininosuccinate lyase. Created with BioRender.com, accessed on 6 February 2021.

Citrulline serves as the direct precursor of arginine (ARG), an amino acid that is involved in several physiological roles including urea cycle function, protein synthesis, creatine and polyamines synthesis, ammonia detoxification, and nitric oxide (NO) synthesis [38], although its priority for utilization under different conditions remains puzzling [40]. Within the intestine and liver, arginine catabolism is increased, largely due to higher arginase expression, subjecting ingested arginine to the first-pass extraction. Contrastingly, L-citrulline bypasses extraction by the gastrointestinal tract (GIT) and liver, promoting the down-stream synthesis of $\mathrm{NO}$ via L-citrulline recycling to L-arginine [11]. Studies have shown that augmenting L-arginine levels as a potential therapeutic mechanism in conditions of NO unavailability/deficiencies may be largely ineffective, since $\mathrm{L}$-arginine is subject to gastrointestinal and hepatic extraction, along with a dose-dependent effect of gastrointestinal distress [11]. Alternatively, the compartmentalization of hepatic L-citrulline metabolism in the urea cycle permits L-citrulline to bypass hepatic catabolism, thus allowing for L-citrulline supplementation to effectively increase the peripheral levels and tissue contents for L-arginine and $\mathrm{NO}[11,23]$. In mice, citrulline supplementation is more efficacious at increasing arginine availability (by 35\%) compared to direct arginine supplementation, since its only fate is conversion to arginine in vivo [42]. Extensive arginine catabolism occurs in the small intestinal mucosa, with proportions of arginine being removed via splanchnic first-pass metabolism (FPM). This catabolism engulfs about $40 \%$ of the luminal arginine in adult rats, 38\% of dietary arginine in adult humans [39], and $~ 70 \%$ in mice with limited quantities entering into peripheral circulation [42], suggesting that significant quantities of supplemental arginine are unavailable to extra-intestinal tissues [39]. Additionally, exogenous L-citrulline administration elevated serum-free contents of amino acids including arginine, citrulline, and ornithine in a dose-dependent manner [43].

The ARG-CIT-ARG inter-organ cycle is a machinery that protects dietary arginine from excessive hepatic degradation (Figure 3), thus maintaining protein homeostasis [44]. Further evidence showed that, during conditions of arginase-induced arginine deficiency, it was L-citrulline supplementation that increased NO concentration and microcirculation in tissues, not L-arginine $[45,46]$. The combination of L-citrulline plus L-arginine produces rapid kinetics in enhancing NO-dependent responses and plasma arginine, greater than arginine alone [47]. Thus, for conditions associated with impaired arginine metabolism, 
arginine deficiencies and NO metabolism disorders, L-citrulline administration offers a potential therapeutic strategy [23].

\subsection{Metabolism of Quercetin}

The pathways through which quercetin is absorbed in the gut of both humans and animals are well documented [48,49]. Absorption of quercetin mostly occurs in the small intestine. Thereafter, it is metabolized by the animal's body. However, due to the difficulty in digesting quercetin in the small intestine, it may undergo further catabolism in the colon initiated by the intestinal microflora to produce bioavailable compounds that are easily absorbed in the form of conjugates with attached groups of sulfate, methyl, or glucuronide [48,49]. Although the main site for quercetin absorption is the small intestine [50], about 5 to $10 \%$ of it undergoes complete absorption in the small intestine, whereas, about 90 to $95 \%$ of quercetin is absorbed in the colon [51-53]. This occurrence is attributed to the fact that glucose groups are attached to quercetin and before quercetin can be absorbed (aglycone, the absorbed unit of quercetin which is very reactive and insoluble in aqueous solution) [54,55], into the enterocyte, the attached sugar molecules or any other chemical substances must be removed, usually by the activities of the brush border enzymes including lactase phloridzin hydrolase (LPH) which removes sugar groups from flavonoids [56]. In comparative terms, the bioavailability of quercetin glycosides is more than quercetin aglycone, because of the insolubility of aglycone in the gut lumen [57-59]. Since the enzymes in the brush border are more glucose-specific, the absorbability of quercetin glucosides is rapid compared to other forms of glycosides such as rutin (quercetin-3-Orutinoside) which, via the actions of enzymes from the intestinal microflora, undergoes deglycosylation to form aglycone [60-63]. Literature has outlined the significance of solubility on quercetin bioavailability in several animal models (mice, rats, humans, pigs, and chickens), stating clearly that the solubility and bioavailability of quercetin can be improved when combined with substances such as alcohol [64], nondigestible oligosaccharides [65], or with a high-fat $(17 \%)$ diet $[66,67]$. When quercetin is absorbed into the enterocytes, it is glucuronidated, sulfated, and methylated by UDP-glucuronosyl transferases (UGTs), sulfotransferases (SULTs), and catechol-O-methyl transferase (COMT), respectively, inhabited in the gut and hepatic cells. This conversion reaction was also confirmed by an in vitro experiment using hepatocytes obtained from rats or humans [68]. The absorption of quercetin is proceeded by its appearance in different biochemical forms in the bloodstream, such as its methylated form. Studies have evaluated the various species of quercetin in blood plasma and reported that conjugates of quercetin represented 78 to $79 \%$, with 8.5 to $11 \%$ existing as isorhamnetin ( $3^{\prime}-\mathrm{O}$-methyl-quercetin), and 10 to $13 \%$ as tamarixetin (4'-Omethyl-quercetin) conjugates $[61,62,67]$. Reports indicated that enterocytes, via multidrug resistance-associated protein 2, help to excrete a substantial percentage of flavonoid conjugates back into the intestinal lumen [69]. Generally, quercetin glucuronides are in a more stable state for transportation into the bloodstream. However, when they are transported into the vascular smooth muscle cells $[70,71]$ and inflammation sites, for instance, they may undergo deconjugation [71-73]. Quercetin glucuronide itself exhibits some diminishing activities in comparison to aglycone, and occasionally the conjugated and/or methylated compounds exhibit some unique bioactivities different from that displayed by the parent compound [74-78].

Some derivatives of quercetin such as rutin cannot be absorbed in the small intestine and so it goes through deglycosylation in the colon by some gut enzymes ( $\beta$-glucosidases and $\alpha$-rhamnosidases) produced by the intestinal microflora. At this site (the colon), some of the deglycosylated rutin will be absorbed and others will undergo gut microbial catabolism into smaller soluble and absorbable molecules [79]. The aglycone then produced will be absorbed by the colonocytes and then transported into the bloodstream or may undergo further gut microbial breakdown to form simpler and more soluble species for easy absorption. Certain strains of gut microbiota including Bacteroides spp., Streptococcus spp., Bifidobacterium spp., Pediococcus spp., and Lactobacillus spp. are involved in the trans- 
formation of quercetin into various phenolic acids including 3,4-dihydroxyphenylacetic, 3-hydroxybenzoic, and 3,4-dihydroxybenzoic acids [80]. Other in vitro reports showed that the contents of porcine hindgut could metabolize quercetin into several species [69]. An in vitro experiment on quercetin fermentation in the colon showed that protocatechuic acid was the main product obtained, whereas $p$-hydroxybenzoic, homovanilic, and phenylacetic acids were also observed but in smaller quantities [81]. Similar products were obtained after exposing quercetin to exhaustive electrochemical hydrolysis [81,82]. In a rat model, the fermentation of quercetin by the intestinal microflora produced important biological acids including propionic acid (3-(3,4-dihydroxyphenyl)) which was further degraded to form 3,4-dihydroxyphenylacetic acid, and, if necessary, could be further fermented to form protocatechuic acid and subsequently 4-hydroxybenzoic acid [83]. The catabolism process continues until simpler forms are obtained and then lastly produces carbon dioxide [83,84]. The metabolic pathways of quercetin metabolism in monogastric and human studies are depicted in Figure 4.

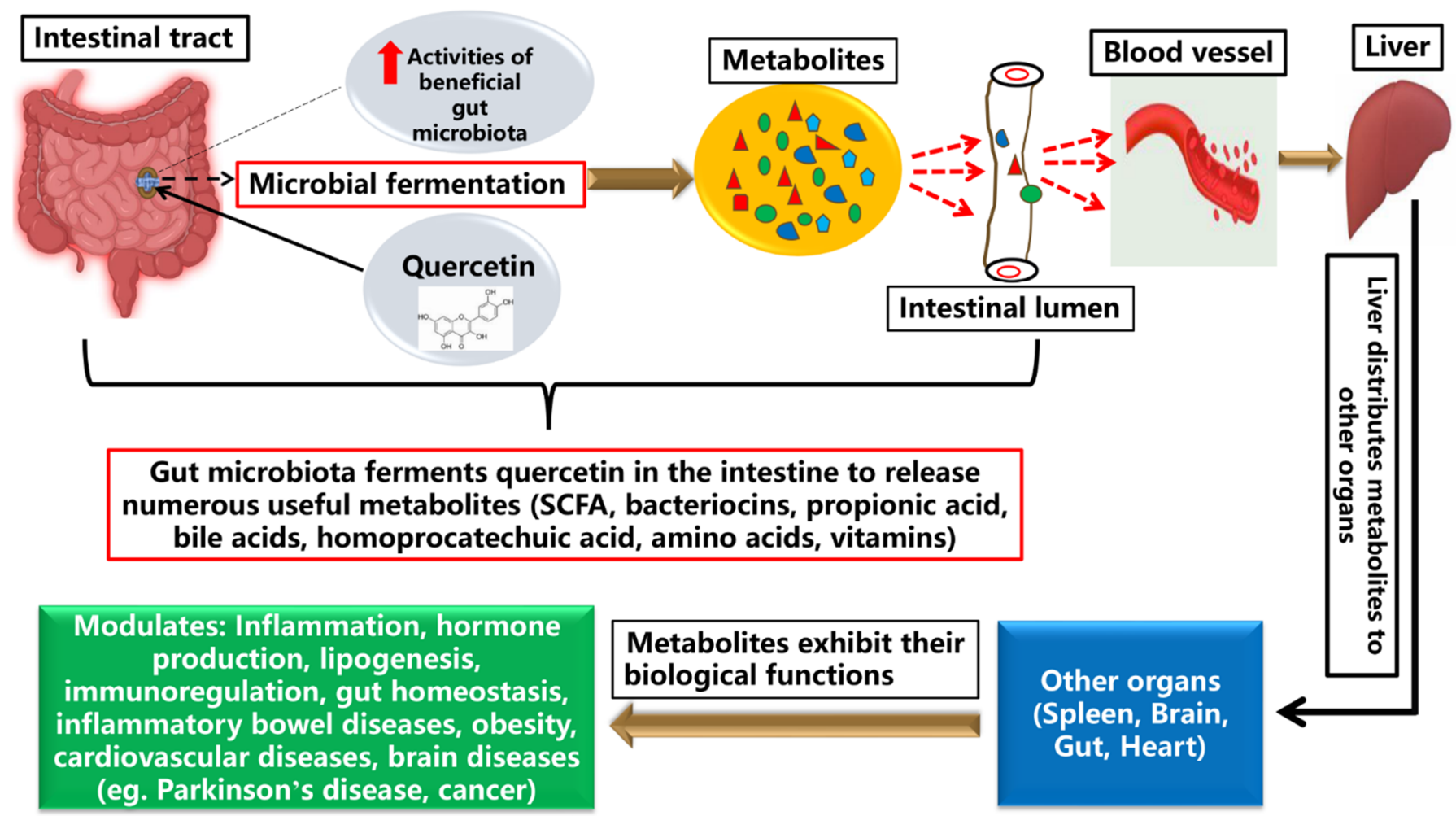

Figure 4. Quercetin is fermented into several metabolites in the gut by numerous gut microbial species. These metabolites are useful substances that are diffused into the blood stream to be distributed to the various organs where their biological activities are exhibited.

\section{Role of Citrulline and Quercetin in Gut Functioning}

\subsection{Effects of Citrulline on Gut Functions of Animals}

Studies have shown the beneficial effects of increased dietary levels of amino acids on gut development, functions, and immune defense of animals during normal conditions and periods of intestinal challenge [85]. Citrulline has been identified as a gut metabolite, and although it is a non-protein amino acid, it can be synthesized from several amino acids in the enterocytes [86]. Circulating citrulline levels can serve as biological markers in the assessment of mucosal damage. For instance, the loss of small bowel epithelial cell mass is reflected by lowered circulating citrulline levels [87]. There exists an association between plasma citrulline and intestinal enterocyte mass, as well as the small bowel remnant length. Therefore, plasma citrulline derived from the small intestine can depict intestinal failure independent of the nutritional and inflammatory state $[36,88]$. Plasma citrulline 
had been shown to relate positively with small intestinal absorptive capacity $[89,90]$, and negatively with the extent of mucosal damage [91]. In addition, the relative decrease in plasma citrulline correlated with pathological findings of crypt necrosis, villus atrophy, and enterocyte loss [92]. Therefore, citrulline is widely considered as a blood biomarker for gastrointestinal functioning [36].

Citrulline concentration depicts overall small bowel functioning and provides reliable information on global gut absorption [37]. Citrulline pretreatment improved gut barrier integrity and reduced bacterial translocation in ileum mucosa [13]. It serves as an indicator for early acute intestinal dysfunction, such that reduction in the number and functions of intestinal epithelial cells would result in decreased serum citrulline levels [93]. Moreover, significant correlations have been established between plasma citrulline concentration and small bowel length, and villous atrophy [36]. Citrulline also exhibited protective effects against inflammatory changes and intestinal permeability, by improving the expression of tight junction proteins (occludin and zona occludins-1) during early-staged dietary-induced non-alcoholic liver disease (NAFLD) in mice [94].

The gut microbiota is critically involved in the pathogenesis of immune diseases. It influences the host's innate immune response through alterations in immunological mediators, such as cytokines and chemokines [95]. In understanding gut microbiota dysbiosis, alterations in enterocyte function, identified with lowered blood citrulline, was associated with increased abundance of Flavobacteriaceae and decreased abundance of Streptococcaceae and Lachnospiraceae [96]. This further indicated the existing linkage between enterocyte functioning and gut microbiota in the development of metabolic complications. Joint analysis of the microbiome, intestinal metabolites, and hepatic mRNA sequence showed a highly positive association ( I correlation | > 0.9) between primary bacteria (Lactobacillus, Bifidobacterium, Streptococcus, Ruminococcaceae, Oscillospira, Peptococcaceae, Roseburia, RF39, Turicibacter, and Veillonella), key hepatic genes, and major metabolites including citrulline, histidine, isoleucine, guanine, deoxycholic acid, galacturonic acid, and glucuronic acid [97]. Ho, El-Nezami, and Shah [98] demonstrated the synergistic effect of citrulline and Lactobacillus helveticus strain in promoting intestinal epithelial barrier functions, revealing the prebiotic properties of citrulline.

As an amino acid that is highly abundant in watermelon [99], supplementation of watermelon products altered the cecal microbiome in high-fat-diet (HFD)-fed mice causing distinct shifts in the relative abundance of Bacteroides genus, and a decrease in Clostridiales bacteria, and family Ruminococcaceae with the intake of watermelon products [100]. In HFDfed mice, treatment with watermelon products (fiber, rind, and seed) significantly elevated the hepatic citrulline levels, especially using the watermelon seed, and further influenced metabolites involved in lipid metabolism by reducing long-chain FA (LCFA) stearate, bile acids contents (cholate, $\beta$-muricholate, and tauro- $\beta$ muricholate), and arachidonic acid derivatives (12-hydroxyeicosatetraenoic acid (12-HETE) and 15-HETE). This implied an enterohepatic recirculation and anti-inflammatory role [100]. In probiotic-fed groups, dietary supplementation with Lactococcus lactis WFLU12 greatly influenced metabolic pathways by increasing citrulline production to promote growth regulation and gut development in fish [101]. Fecal metabolomics of type 2 diabetic nephropathy (T2DN) rats identified citrulline as a metabolic marker involved in the urea cycle and closely implicated in the improvement of T2DN, protecting against inflammation and renal damage [102]. Furthermore, to investigate the adverse impact of phthalate-related disruption in zebrafish, it was discovered that microbial metabolites including the citrulline levels were lowered, which may have had additive effects on the immune cells and enterocyte functioning [103]. Table 1 gives a summary of studies that demonstrated the functional roles of citrulline in modulating intestinal immunity and gut health. 
Table 1. Summarized roles of citrulline in promoting intestinal immune response and gut health in human and animal models.

Subject Design

References

In treated animals, a $>50 \%$ decrease in plasma L-citrulline levels strongly correlated with histopathological findings

Wistar rats; Beagle dogs; Cynomolgus monkeys Intestinal toxicity was induced using oncological drug candidates.

in the small intestine such as single-cell necrosis and mucosa atrophy intestinal crypt necrosis, villus atrophy, enterocyte loss, and clinical signs (bloody feces and diarrhea), indicating L-citrulline as a small signs (bloody feces and diarrhea), indicati
intestine biomarke

\begin{tabular}{|c|c|c|c|}
\hline Dogs ( 5 males / 5 females per group) & $\begin{array}{c}\text { Oral doses of } 0.75,1.5 \text {, and } 3 \mathrm{mg} / \mathrm{kg} / \mathrm{d} \text { of MS-229 over } 4 \text { weeks } \\
\text { to induce small intestinal toxicity. }\end{array}$ & $\begin{array}{l}\text { A dose- and exposure-dependent decrease in plasma citrulline was } \\
\text { correlated with pathological findings in the small intestine. }\end{array}$ & [105] \\
\hline Preterm infants & $\begin{array}{c}\text { Plasma citrulline levels were measured during the first } 48 \mathrm{~h} \text { after } \\
\text { necrotizing enterocolitis onset. }\end{array}$ & $\begin{array}{l}\text { Plasma citrulline decreased in the first } 48 \mathrm{~h} \text { suggesting ongoing } \\
\text { intestinal injury, thus plasma citrulline measurement may provide an } \\
\text { indication for intestinal recovery rate during the first } 24 \mathrm{~h} \text { after NEC } \\
\text { onset. }\end{array}$ & [106] \\
\hline Male Wistar rats $(n=46 ; 230-250 \mathrm{~g})$ & $\begin{array}{l}\text { Varying citrulline levels were administered as } 0.5,1,2.5 \\
\qquad 5 \mathrm{~g} / \mathrm{kg} / \mathrm{d} \text { citrulline. }\end{array}$ & $\begin{array}{l}\text { The jejunum weight was significantly positively correlated with } \\
\text { plasma citrulline, suggesting a dose-dependent intestinal adaptation } \\
\text { in gut resected rats. }\end{array}$ & [107] \\
\hline In vitro analysis using IPEC-J2 cells & $\begin{array}{l}\text { Citrulline (2 mM) and Lactobacillus helveticus ASCC } 511 \text { were } \\
\text { co-treated to IPEC-J2 cells. }\end{array}$ & $\begin{array}{l}\text { Lactobacillus helveticus and citrulline exhibited synergistic effects } \\
\text { against adhesion of pathogenic bacteria, Escherichia coli; stimulated } \\
\text { nitric oxide; improved transepithelial electrical resistance; and } \\
\text { stimulated tight junction proteins expression, thus, promoting } \\
\text { intestinal health. }\end{array}$ & [98] \\
\hline Female C57BL/6J mice & $\begin{array}{l}\text { Mice were induced non-alcoholic steatohepatitis using fat-, } \\
\text { fructose-, and cholesterol-rich diet followed by }+/-2.5 \mathrm{~g} \mathrm{~L} \\
\text {-citrulline } / \mathrm{kg} \text { body weight. }\end{array}$ & $\begin{array}{l}\text { L-citrulline alleviated non-alcoholic fatty liver disease progression } \\
\text { via attenuation of bacterial endotoxin translocation and the loss of } \\
\text { tight junction proteins in small intestinal tissue. }\end{array}$ & [108] \\
\hline Human model & $\begin{array}{l}\text { Randomized, double-blind crossover study, } 10 \text { men cycled for } \\
60 \text { min at 70\% of their maximum workload after L-citrulline } \\
\text { (10 g) or placebo (L-alanine) intake. }\end{array}$ & $\begin{array}{c}\text { Pre-exercise L-citrulline intake prevented splanchnic } \\
\text { hypoperfusion-induced intestinal compromise by preserving } \\
\text { splanchnic perfusion and attenuated intestinal injury during exercise } \\
\text { probably by enhancing arginine availability. }\end{array}$ & [109] \\
\hline
\end{tabular}


Table 1. Cont.

\section{Subject}

Design

\section{Main Findings}

References

Citrulline pretreatment preserved barrier integrity and modulated

immune response via decreasing intestinal permeability and

Mice undergoing intestinal obstruction were divided into three groups: sham, intestinal obstruction, and citrulline group receiving a diet containing $0.6 \%$ citrulline. increased secretory IgA concentration.

Citrulline provided protective effects by lowering the peripheral

blood monocytes, the infiltration of CD68-positive monocytes, and effects in ulcerative colitis rats.
Male Wistar rats $(n=15)$ administered intragastrically for $7 \mathrm{~d}$.
L-citrulline elicited gastro-protective effects by attenuating gastric lesions, prevented oxidative damage, decreased nitric oxide content and increased the myeloperoxidase activity

Adult male Sprague-Dawley rats (180-220 g)

L-citrulline (300, 600, and $900 \mathrm{mg} / \mathrm{kg}$ body weight) was administered to rats having ethanol-induced gastric ulcer in rats.

Rats were assigned to either citrulline, arginine, control, or sham roups. The sham group underwent transection and other groups had

Citrulline increased arginine levels and improved nitrogen balance after massive intestinal resection.

L-citrulline reduced the gastric mucosal lesion, prevented the production of lipid peroxidation, and inhibited the increase in

Adult male Sprague-Dawley rats (200-240 g) ischemia/reperfused rats.

$$
\text { myeloperoxidase activity. }
$$

During endotoxemia, L-citrulline supplementation reduced intestinal microcirculatory dysfunction and increased intracellula NO production via increasing plasma and tissue concentrations of arginine and citrulline, and restored intracellular NO production in the intestine. Jejunal tissues in the L-citrulline group showed an increase in degree of phosphorylation of eNOS phosphorylation and decreased iNOS protein level. bodyweight per h) combined with either L-citrulline $(6.25 \mathrm{mg} / \mathrm{h})$, L-arginine $(6.25 \mathrm{mg} / \mathrm{h})$, or L-alanine $(12.5 \mathrm{mg} / \mathrm{h})$

Mice received supplemented citrulline or alanine in the drinking water for $10 \mathrm{~d}(1 \mathrm{~g} / \mathrm{kg} / \mathrm{d})$ and on the seventh day, the animals were injected intraperitoneally with a single dose of

Swiss male mice (6 weeks old) phosphate-buffered saline (PBS) or 5-fluorouracil $(200 \mathrm{mg} / \mathrm{kg})$ for the induction of mucositis.
Citrulline administration contributed to a partial recovery of the

mucosal architecture in mucositis-induced mice. There was an

intermediate reduction in the histopathologic score, and functional intestinal permeability was partially rescued by citrulline treatment.

Citrulline attenuated mucosal damage by reducing the size of the 


\subsection{Effects of Quercetin on Gut Functions of Animals}

Quercetin enhances intestinal barrier function and modulates gut microbiota composition. The activities of tight junction proteins at the gut epithelium enhance barrier functions and reduce inflammation, protecting the host from colonic diseases [115]. Quercetin promotes the assembly of tight junction proteins such as ZO-2, occludin, claudin-1, and claudin-4 expression by inhibiting the PKC $\delta$ isoform [115]. Quercetin induced the remodeling of epithelial tight junctions and enhanced barrier integrity in the Caco-2 gastrointestinal epithelial cell model [116]. Studies have directly employed the use of specific metabolites produced by gut bacteria (such as Bifidobacterium pseudocatenulatum INIA P815 strain [3], Lactobacillus, Clostridium, and Bacteroides [4]) from flavonoids, including quercetin, as therapeutic agents in treating diseases such as inflammatory bowel disease (IBD). It was shown that Urolithin A, UAS03, and L-tryptophan mitigated IBDs by increasing epithelial cell junction proteins in the gut, and reduced gut inflammation [3,4]. These metabolites did not only act to reduce inflammation but also restored gut barrier integrity and protected against colitis [3,4]. Wu et al. (2019) outlined that L-tryptophan, a metabolite obtained from quercetin metabolism, serves as a nutrient enhancer, as well as in the regulation of the kynurenine pathway and immune responses in the mice model.

Quercetin is transformed by the gut microbes (B. fragilis, Lactobacillus L-2, C. perfringens, E. ramulus, Bifidobacterium B-9, Streptococcus S-2, and Bacteroides JY-6) into several metabolites including 3,4-dihydroxybenzoic acid, 4-hydroxybenzoic acid, 3,4-dihydroxyphenylacetic acid (homoprocatechuic acid), and 3-(3-hydroxyphenyl) propionic acid [79]. The 3,4-dihydroxy phenylacetic acid was reported as an active flavonoid metabolite that prevents liver damage by upregulating transcription factor nuclear factor (erythroid-derived 2)-like 2 (Nrf2) [117], and also exhibited a strong anxiolytic effect in mice model [118]. However, 3-(3-hydroxyphenyl) propionic acid showed a significant vasodilatory effect in rats, by modulating the endothelial nitric oxide synthase (eNOS)-derived nitric oxide (NO) [111]. Lastly, 4-hydroxybenzoic acid was also reported to be involved in the scavenging activities of free radicals and inhibition of trypsin activity [119]. Quercetin can reshape gut microbiota to alleviate several diseases [28]. In antibiotic-treated mice, quercetin supplementation improved the diversity of the gut bacterial community, increased the length of intestinal villi, and improved mucosal thickness [120]. Another study also reported that quercetin suppressed the production of pro-inflammatory cytokines, such as interleukin (IL)-17, TNF- $\alpha$, and IL-6 in the colon tissues, and enhanced the population of Bacteroides, Bifidobacterium, Lactobacillus, and Clostridia, but significantly reduced those of Fusobacterium and Enterococcus [121]. Quercetin also inhibited the growth of Porphyromonas gingivalis, Actinomyces viscosus, Fusobacterium nucleatum, Actinomyces naeslundii, and Helicobacter pylori [121]. Moreover, it has been proposed that quercetin similarly affects the gut microbiota as tea catechins and other flavonoids [122]. However, further studies are necessary to expound on this (Figure 5). 

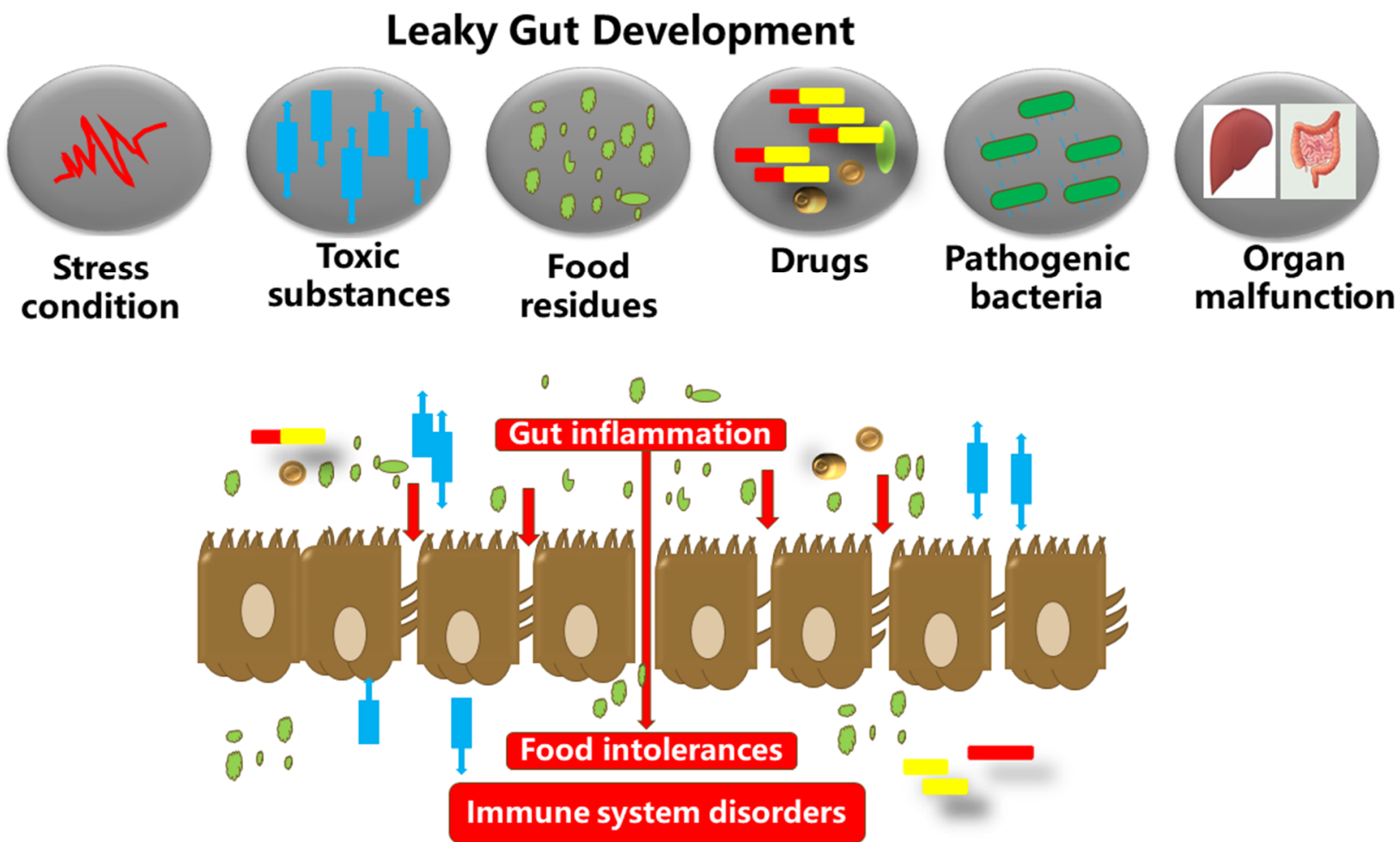

Figure 5. The gut microbiota, food substances, and the gut epithelium are in proximity. Dysbiosis in the gut microbiota could inversely increase the gut permeability. This results in autoimmune and neurodegenerative disorders, and excessive inflammation in the gut epithelium, which in turn degenerates the tight junction proteins and membranes (occludin, claudins, junctional adhesion molecules, and tri-cellulin, ZO-1, and cingulin). The tight junction barriers are disrupted by the invasion of toxic substances (bacterial endotoxins, metabolites, food particles, drugs, etc.), resulting in barrier dysfunction and severe inflammatory disorders such as IBDs.

Reports indicated that supplementing quercetin in a high-fat-diet-fed mice model modulated gut microbiota composition via lessening the activation of the lipoperoxidationdependent TLR-4 pathway [123]. Another study confirmed the prebiotic role of quercetin as it reduced the abundance of atherogenic-related bacteria (Verrocomicrobia) and the abundance of atherogenic lipid metabolites but increased the abundance of Firmicutes, Cyanobacteria, and Actinobacteria [124]. Quercetin increased the diversity of microbiota inhabiting the colon of mice infected with Citrobacter rodentium, hence lessening colitis and decreasing pro-inflammatory cytokines [125]. Recently, it was demonstrated that quercetin improved gut dysbiosis in antibiotic-treated mice by successfully increasing the diversity of the gut microbiota, and restored barrier functions through decreased expressions of serum D-lactic acid and serum diamine oxidase activity [110]. Additionally, quercetin supplementation increased the relative abundance of Lactobacillus in the cecum, and the expression of tight junction proteins (mucin-2 and tight junction protein 1) was downregulated [121]. Cumulatively, these reports provide evidence for quercetin's role in improving gut barrier functions, preventing inflammatory bowel diseases, and promoting the composition of beneficial microbiota (Table 2). 
Table 2. Summarized roles of quercetin in enhancing intestinal immunity and gut health in human and animal models.

Subject

Design

Main Findings

References

Quercetin treatment to high-fat-diet-fed mice attenuated

atherosclerotic lesions, elicited protective effects against

immune/inflammatory responses and oxidative stress, and

Mice were randomly assigned to either the quercetin treatmen (90 days old; $(24.76 \pm 0.37 \mathrm{~g})$ $(100 \mu \mathrm{g} / \mathrm{d} ; n=12)$ or the control group $(n=12)$ and fed regula chow diet for 4 weeks, followed by a high-fat diet until 12 weeks. decreased intestinal lipid levels. Additionally, quercetin altered the gut microbiota composition by decreasing the abundance of abundances of Actinobacteria, Cyanobacteria, and Firmicutes.

Quercetin reduced the lipid level, areas of atherosclerotic lesions and sizes of plaques.

Quercetin alleviated Citrobacter rodentium-induced colitis by

suppressing pro-inflammatory cytokines production and modified the gut microbiota by increasing Bacteroides, Bifidobacterium,

C57BL/6 mice and Enterococcus spp.

Quercetin alleviated LPS-induced oxidative stress via the

MAPK/Nrf2 signaling in the intestines of chickens. Quercetin alleviated LPS-induced decrease in duodenal, jejunal, and illeal

Chickens were randomized into four groups: saline-challenged

Broiler chickens $(n=240)$ or $500 \mathrm{mg} / \mathrm{kg}$ of quercetin.

quercetin inhibited LPS-induced jejunal oxidative stress and relieved jejunal mitochondria damage.

Quercetin-supplementation improved intestinal health and alleviated intestinal injury during transport through decreased serum endotoxin levels, lowered intestinal ROS and MDA, and lowered jejunal inflammatory cytokines expression, but increased Pigs were randomly assigned to either a control group fed bas with $25 \mathrm{mg} / \mathrm{kg}$ feed quercetin, and after a 4-week period, pigs were transported for $5 \mathrm{~h}$

jejunum villi height and upregulated the mRNA expression of occludin and zonula occudens- 1 in the jejunum.

Quercetin elicited an analgesic effect on PI-IBS and decreased the visceral pain threshold of PI-IBS rats, and the abdominal motor Post-inflammatory irritable bowel syndrome (PI-IBS) model rats were administered quercetin by gavage at doses of 5,10 , and $20 \mathrm{mg} / \mathrm{kg}$ for $14 \mathrm{~d}$.

Rats were grouped as osteoarthritis-induced model,

response to colon distension was markedly increased. Quercetin also

reduced the colonic expression of genes responsible for enteroendocrine cell differentiation.

Quercetin partially abrogated intestinal flora disorder and reversed fecal metabolite abnormalities. Diversity in the gut microbiota was decreased after quercetin treatment and at the genus level, Lactobacillus was increased whereas, unidentified Ruminococcaceae was decreased. 
Table 2. Cont.

\section{Subject}

Design

groups of broiler chickens at concentration of 200,400 , and $800 \mathrm{ppm}$, and a control group was supplemented with a basal diet.

Ross 308 chicks ( $n=128$ chicks; 41 gm $/$ chick)

Monosodium glutamate (MSG)-treated mice were randomly divided into two groups: MSG group and quercetin group (5 mg/kg quercetin) administrated by gavage at a dose of

C57BL/6J mice

$$
100 \mu \mathrm{L} / 10 \mathrm{~g} / \text { body weight (BW)/ d for } 6 \text { weeks. }
$$

Wistar rats $(n=23)$

Wistar rats were randomized into four groups fed a high-fat sucrose diet supplemented or not with trans-resveratrol (15 mg/ $\mathrm{kg}$ body weight $(\mathrm{BW}) / \mathrm{d})$, quercetin $(30 \mathrm{mg} / \mathrm{kg} \mathrm{BW} / \mathrm{d}$ ), or a combination of both polyphenols.

Mice were challenged with high-fat diet (HFD) supplemented or not with quercetin $(0.05 \%(\mathrm{wt} / \mathrm{wt})$ aglycone quercetin) for 16 weeks.

Mice were administrated $0.5 \mathrm{~mL} / \mathrm{d}$ antibiotics cocktail

Kunming male mice $(n=36 ; 18-20 \mathrm{~g})$ tragastrically for $7 \mathrm{~d}$ mice were fed AIN-93G diet containing $0.2 \%$ quercetin for $10 \mathrm{~d}$.

Quercetin $(50 \mathrm{mg} / \mathrm{kg} / \mathrm{d})$ was dissolved in distilled water and administered daily by gavage at $10 \mathrm{~mL} / \mathrm{kg}$ for 12 weeks to

Sprague-Dawley rat (6 weeks old; male; 160-200 g)

\section{Main findings}

References

Dietary quercetin improved the gut microbiota environment by decreasing total coliforms and Clostridium perfringens population but increased the Lactobacillus counts. Further, the intestinal mRNA expression of intestinal $\mathrm{Cu} / \mathrm{Zn}$-superoxide dismutase, glutathione peroxidase, and nutritional transporters was upregulated in quercetin-supplemented groups

Dietary quercetin attenuated MSG-induced gut microbiota dysbiosis and improved intestinal barrier function. Quercetin reversed

MSG-induced elevation in Firmicutes abundance and decreased the Firmicutes / Bacteroidetes ratio. Further, Lachnospiraceae and Ruminicoccaceae abundance was reduced. Colon damage was recovered and Muc2 and ZO-1 expression was upregulated after quercetin treatment.

Quercetin supplementation eliminated gut dysbiosis by attenuating Firmicutes / Bacteroidetes ratio and inhibited the growth of bacterial

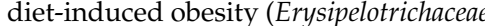
Bacillus, Eubacterium cylindroides).

Quercetin alleviated obesity-associated NAFLD via its anti-inflammatory, antioxidant, and prebiotic integrative response. Quercetin reverted gut microbiota imbalance and related endotoxemia-mediated TLR-4 pathway induction, with subsequen inhibition of inflammasome response and reticulum stress pathway activation.

Quercetin supplementation combated gut dysbiosis since it recovered intestinal barrier function and improved the diversity of he gut bacterial community in antibiotic-treated mice. Intestinal villi length and mucosal thickness were increased and butyrate

production was enhanced in quercetin-treated mice.

Quercetin exerted a neuroprotective effect and modulated gut microbiota associated with DPN phenotypes and ROS production in

STZ-induced DPN rats. Quercetin rescued gut dysbiosis by decreasing four potential pathogenic species and enriching two prebiotic species associated with DPN phenotypes and ROS production.

$$
\text { (DPN) rats. }
$$




\subsection{Potential Combinatory Roles for Citrulline and Quercetin in Gastrointestinal Health of Animals}

In the following section, we discuss the potential of utilizing both L-citrulline and quercetin together on specific aspects of gut health and immunity. The gastrointestinal tract environment is exposed to several commensal bacteria, and dietary modifiers, such as, probiotics, prebiotics, symbiotic, polyphenols, amino acids, and other bioactive compounds, which have been demonstrated to beneficially impact gut health and host welfare [133]. Gut health is principally affected by two important factors, the intestinal barrier and gut microbiota [133]. Tight junctions comprise of transmembrane proteins (such as occludin, claudins, junctional adhesion molecules, and tri-cellulin) and peripheral membrane proteins (ZO-1 and cingulin), which function to regulate paracellular permeability and gut barrier integrity [3]. Tight junction disruption leads to barrier dysfunction and this is implicated in the pathology of inflammatory bowel diseases (IBDs) [121] (Figure 5). Specifically, gut barrier dysfunction allows for bacterial invasion and excessive inflammation in the gut [3]. The release of inflammatory cytokines and growth factors such as interferon- $\gamma$ (IFN- $\gamma$ ), TNF- $\alpha$, IL-1 $\beta$, and TGF- $\alpha$, platelet-derived growth factors, and bacterial endotoxins, further alters the tight junctions, increasing permeability [3]. Dysbiosis in the gut microbiota increases gut permeability (preferably called leaky gut) and significantly paves way for the pathogenesis of several disorders, such as autoimmune and neurodegenerative disorders $[125,134]$. As such, the leaky gut is mainly caused by excessive inflammation in the gut epithelium, which in turn degenerates the tight junction proteins [3]. On this note, it is evident that barrier dysfunction and inflammation are the main inter-correlated conditions that permit the occurrence of IBDs, and hence, alleviating these conditions is crucial for mitigating the disease progression (Figure 6). Noteworthy is the fact that IBD pathogenesis is influenced by several contributing factors, including environmental, genetic, inflammatory factors, oxidative stress, and intestinal microbiota [125,134].

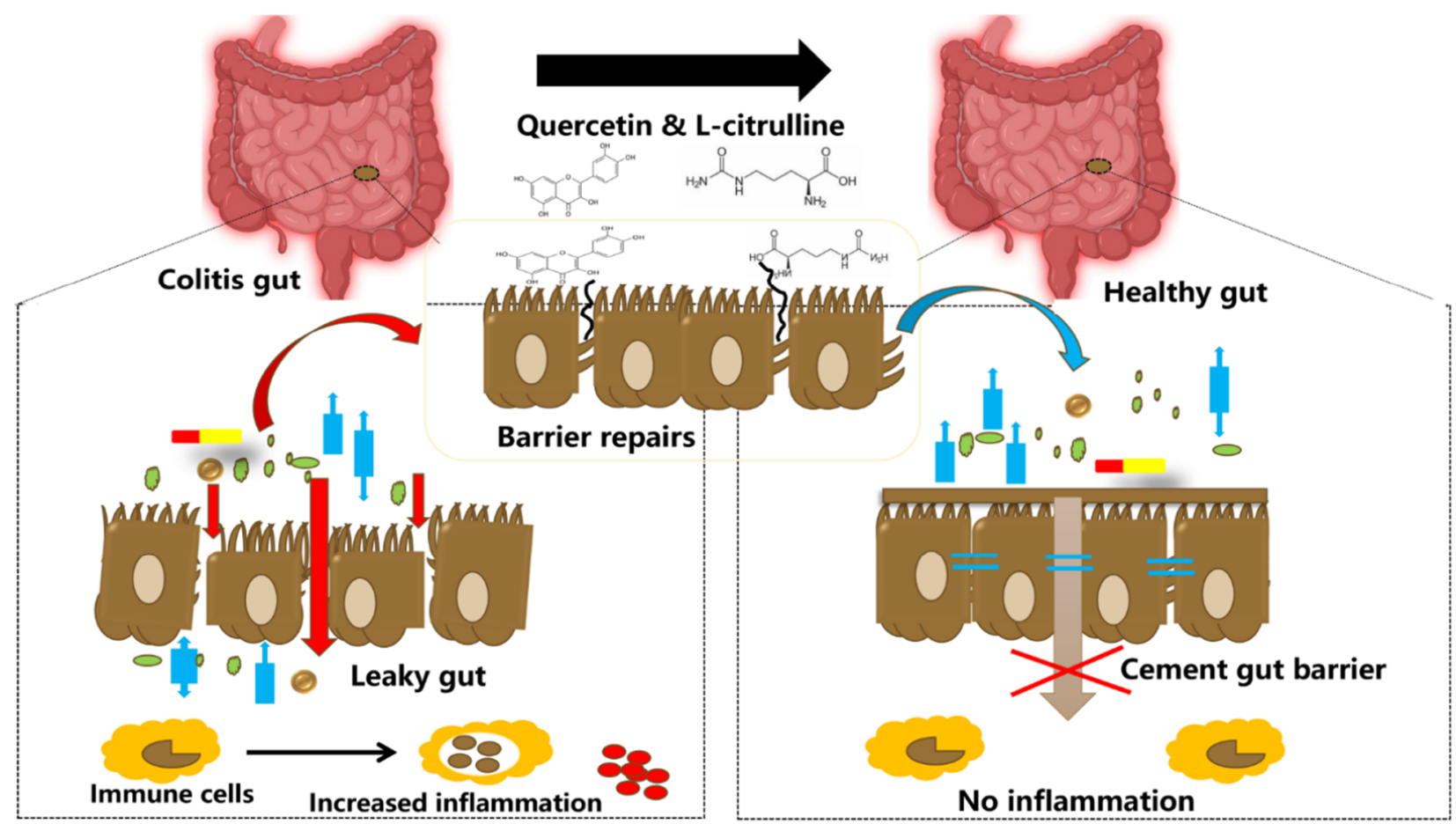

Figure 6. Illustration showing tightening of the gut barrier cells and reduced inflammation due to the introduction of quercetin and L-citrulline.

This development has prompted research on several nutritional interventions including plant-based flavonoids, organic/inorganic metabolites [3], and amino acids that displayed potent anti-inflammatory, gut-protective, and antioxidative properties [4]. Ad- 
ditionally, there exists crosstalk between the gut microbiota and enterocytes that shape the gut environment, which intensely affects the intestinal immune homeostasis $[3,88]$. Changes in the gut microbiota can modulate the host's metabolic phenotype and immune status, and in turn, the immune system shapes the composition of the gut microbiota [88].

(a) Anti-inflammatory and immunomodulatory functions

Plasma citrulline level has been extensively adopted in research to establish its role as a reliable and quantitative biomarker of intestinal diseases. Citrulline has been demonstrated as efficacious in IBD models typically induced as Crohn's disease or ulcerative colitis [88]. Using an ulcerative colitis model in rats, citrulline supplementation elicited protective effects in restoring body weight, and lowered the histopathology score and pro-inflammatory factors (MCP-1, IL-6, IL-17A, and p-STAT3) in colon tissues, possibly by improving the structural integrity and absorptive function of the intestine [135]. Citrulline is a reliable marker of intestinal malabsorption [136], and besides its role as a marker of enterocyte function, citrulline has been found to reflect gut dysbiosis induced by antibiotics [137]. L-citrulline alleviated the gastric mucosal lesions and inhibited malondialdehyde (MDA) and myeloperoxidase (MPO) activity during ischemia-reperfusion in rats, thus eliciting protective effects on gastric mucus synthesis and secretion [113]. Further, plasma citrulline levels are elevated in multiple sclerosis [138]. Thus, citrulline is a validated marker of intestinal barrier functions and disorders $[13,37]$.

Studies in immunonutrition have targeted arginine supply, considering its essential role as a substrate for NO production by macrophages [14]. Interestingly, reports showed that citrulline has the potential to act as an immunonutrient to modulate host defense. In vitro and in vivo investigations showed that citrulline may directly influence macrophage function and modify NO production [139]. During mycobacterial infections, $\mathrm{T}$ cells can metabolize L-citrulline to replenish intracellular L-arginine to maintain cellular proliferation, cytokine production, and inflammatory function [140]. In diabetic obese rats, the associated macrophage dysfunction was attenuated with citrulline administration to initiate NO production and regulation of TNF- $\alpha$ and IL- 6 cytokines [141]. In infantile rats, both L-arginine and L-citrulline modulated regulatory T-cell functions [142]. Plasma citrulline further reflects on acute intestinal impairment, since it decreases at the onset of digestive bacterial translocation and septic shock [143]. A study reported a lowered number of inflammatory biomarkers following citrulline supplementation [144]. It acted as an anti-inflammatory agent, characterized by reduction in pro-inflammatory cytokines, along with increase in anti-inflammatory cytokines. L-citrulline exerted protective effects by reducing IL-1 $\beta$ and IL-12, but increased IL-10 generation [145]. Citrulline has been shown to induce anti-inflammatory cytokines (IL-10 and TGF $\beta$ ), while downregulating the pro-inflammatory (IL-1 $\beta$ and MMP9) genes related to leucocyte migration [146]. In ulcerated rats, citrulline pre-treatment attenuated the elevation in IL-6, iNOS, and MPO activities during ethanol challenge [19]. Citrulline was inversely correlated with biomarkers of systemic inflammation, such as C-reactive protein and ferritin concentrations [147].

It is well known that quercetin interacts with other dietary components, such as selenium, polyunsaturated fatty acids, sulfur-containing amino acids, minerals, and other antioxidants including resveratrol [28] to improve gut function and immunity in animals [2]. Quercetin has the potential to confer cell-mediated immunity via downregulation of inflammatory cytokines gene expression [148]. In heterophils, quercetin showed antiinflammatory function by suppressing pro-inflammatory cytokines and several ROS-related gene expressions to combat fungal infections [148]. Dietary quercetin supplementation improved the secretion of immunoglobulins (IgA and $\operatorname{IgM}$ ), and cytokines networks including IL-4, TNF- $\alpha$, TRAF2, and TNFRSF1B [149]. Along with other polyphenols, including resveratrol and tea polyphenols, quercetin has been proposed for IBD and colitis treatment to attenuate inflammation, as they can regulate various cytokines and chemokines expression, as well as inhibit nuclear factor-kappa B (NF- $\mathrm{kB}$ ) transcription (a vital factor for the initiation of an inflammatory response) [150]. They modulated the NF- $\mathrm{kB}$ activation cascade by blocking IKK activation, which inhibits IKBs phosphorylation or degradation 
and the nuclear translocation of p50/p65 [151]. Dietary quercetin is a promising strategy for IBD amelioration following its capacity to restore intestinal immune hemostasis and enteric commensal microflora balance via modulating the Nrf2/HO-1 pathway [152]. In colon tissues, dietary quercetin $(30 \mathrm{mg} / \mathrm{kg}$ ) attenuated colitis severity by modifying gut microbiota population (increased Bacteroides, Bifidobacterium, Lactobacillus, and Clostridia, with reduction in Fusobacterium and Enterococcus populations) and inflammatory cytokines milieu (promoted IL-10 production, but reduced pro-inflammatory cytokines, such as IL-17, TNF- $\alpha$, and IL-6) [125]. However, there exist several inflammatory bowel disease models applied for research, and they differ in their immune and pathophysiological characteristics, which may give rise to discrepancies. For instance, it had been explained that quercetin was unable to ameliorate DSS-induced colitis due to its absorption by glycosides in the small intestine. Therefore, quercetin prodrugs, such as rutin and quercitrin, were shown to facilitate quercetin's release in the colon [153]. Quercetin's glycoside, rutin, has also been demonstrated as a therapeutic agent against IBD, since it can serve as a prodrug for quercetin delivery near IBD sites, alongside its antioxidative and anti-inflammatory effects [154].

\section{(b) Nitric oxide regulation}

L-citrulline, as a functional amino acid with biological functions including cellular metabolism and organ function [37], is also an efficient precursor for NO synthesis [43]. $\mathrm{NO}$ is involved in multiple physiological processes in the GIT, particularly the regulation of gastrointestinal motility, gastroprotection, and mucosal blood flow [35]. However, higher $\mathrm{NO}$ concentrations are toxic since NO reacts with superoxide anion to form peroxynitrite, which in turn promotes cytotoxicity, inflammation, oxidative stress, and increased intestinal epithelial permeability [155], key features of IBD. Studies suggest that IBD is associated with elevated iNOS activity, and as such, increased NO production [35]. Circulating levels of nitrite and nitrate (NO metabolites) were increased and positively associated with intestinal iNOS activity during ulcerative colitis and Crohn's diseases [35,156]. Contrarily, in another report, animal models of experimental IBD showed that both constitutive and inducible NO production were beneficial during acute colitis, although prolonged upregulation of NO was detrimental [157]. Using Argininosuccinate lyase (ASL) knockout mice induced with colitis, it was revealed that enterocytes-derived NO alleviated colitis by reducing macrophage infiltration and tissue damage [158]. However, NO derived from the immune cells was responsible for macrophage activation and increased severity of inflammation [158]. This finding reveals that the specific intracellular source of NO may be implicated in the NO positive and/or negative role during IBD pathogenesis. Interesting is the capacity for citrulline to not only act as an arginine precursor for $\mathrm{NO}$ production, but also the question of citrulline's involvement in NO regulation during biological processes. Impairment in citrulline availability and de novo arginine synthesis reduced NO production but was restored with citrulline supplementation [159]. Thus, citrulline is implicated in the regulation of NO production for homeostasis, as against $\mathrm{NO}$ overproduction and toxicity [160].

NO plays an important role as an endogenous vasodilator and promotes endothelial functions in the gastrointestinal system [161]. Studies have shown that quercetin augments NO production and vasodilation via eNOS activation [162], eliminating endothelial dysfunction [163]. In addition, quercetin was shown to induce vasodilation by enhancing NO synthesis and promoting intracellular calcium-activated potassium channels [164]. Quercetin exerted endothelium-dependent vasodilatations via invoking sustained nitric oxide release in mesenteric vascular beds isolated from rats [165]. Quercetin also restored the intravascular homeostasis and endothelial functions, by attenuating excess NO production induced by ATP, decreased intracellular calcium flux, and eNOS activity in vascular endothelial cells [166]. Further, quercetin reversed the endothelial damage arising from excessive NO by attenuating nitrification stress and protecting the endothelial cells [164]. In mice IBD models, quercetin monoglycosides were shown to counteract increased serum NO and oxidative stress resulting from DSS-induced colitis [134]. In euglycemic and diabetic 
rats, quercetin supplementation increased the bioavailability of NO in the jejunum [167]. Furthermore, co-administration of quercetin and/or L-arginine (each $200 \mathrm{mg} / \mathrm{kg}$ body weight) provided protection against cardiotoxicity $[168]$ and hepatotoxicity $[169,170]$ in rat models.

\section{(c) Anti-oxidative functions}

Reactive oxygen species (ROS) generation in the gut has been linked with several inflammatory disorders. Excessive levels of ROS lead to cellular damage, ultimately disrupting the intestinal barrier, increasing gut permeability and tissue damage [171]. Increased oxidative stress is associated with mucosal inflammation during ulcerative colitis [134,171], and an overproduction of ROS may contribute to the progression of this disorder. Using a DSS-induced colitis mice model, treatment with quercetin aglycone alone or quercetin aglycone with monoglycosides counteracted both inflammatory response and oxidative stress, by lowering the malondialdehyde (MDA), reduced glutathione (GSH), serum nitrate (NO), and myeloperoxidase (MPO) concentrations [134]. Under oxidative stress conditions, citrulline and quercetin would be useful in combating ROS and altering the redox status of the gut. Citrulline has been widely known for its antioxidant properties, which has been attributed either to the direct effects of citrulline and/or indirect effects via NO production [160,172]. Citrulline directly mediated antioxidant defense by influencing the enzyme activities of catalase, superoxide dismutase (SOD), and the total antioxidant capacity, but decreased MDA contents, abolishing the degree of lipid peroxidation [43]. L-citrulline was shown to protect the gastric mucosa during ethanol-induced oxidative stress by recovering SOD, and GSH-Px activities approximately to the control levels [19]. Alongside this, as a potent antioxidant, quercetin acts to maintain endogenous antioxidant defenses, and scavenges reactive oxygen species (ROS) via suppressing the synthesis of lipid peroxy radicals [173], and chelating of metal ion [174]. Quercetin-induced antioxidant effects through activating the Nrf2/NRF1 transcription pathway, which upregulates the expression of peroxiredoxins (PRDX3 and PRDX5), an antioxidant family responsible for catalyzing hydrogen peroxide reduction [175]. Nrf2 transcription affects downstream targets such as catalase, superoxide dismutase 1 , glutathione peroxidase 2 , heme oxygenase1 (HO-1), and thioredoxin genes, ameliorating oxidative stress [121]. Further, in vitro cell culture with quercetin showed upregulated phosphorylation for protein kinase B (Akt) and extracellular signal-regulated kinase $1 / 2$ (ERK1/2), with or without hydrogen peroxide treatment, where Akt and ERK1/2 induction plays protective roles against oxidative stress [176]. Moreover, during intestinal oxidative stress, quercetin restores the normal redox status, in addition to promoting intestinal calcium absorption via glutathione and the glutathione-dependent enzymes system [32]. These findings suggest that both citrulline and quercetin treatment promote the antioxidant machinery by elevating antioxidant enzyme levels, and reduce the levels of ROS and lipid peroxidation products. We consider this particularly useful in conditions such as heat stress, which is closely associated with oxidative stress [177], since heat stress tends to influences the metabolic rate, antioxidant defenses, immune function, inflammatory status, gut functions, reproductive ability, organ functioning, and in severe cases, the lifespan of the animals [178-180].

(d) In vitro effects of citrulline and quercetin on intestinal cell integrity

Studies have reported on the in vitro effects exerted by citrulline and quercetin on the cellular intestinal integrity. For instance, Chapman et al. [181] reported that arginine (synthesized from citrulline) and citrulline (key precursor of arginine) protected the intestinal cell monolayer tight junctions from hypoxia-induced injury in piglets. They further demonstrated that NO played a major role in the protective effects of arginine and citrulline during intestinal epithelial hypoxia [181]. This suggests the beneficial role of NO in the maintenance of intestinal barrier functions. During arginine supplementation, $\mathrm{NO}$ was implicated in cell migration in razor-injured porcine intestinal epithelial cell monolayers [182]. Further, NO derived from iNOS following arginine and citrulline supplementation was involved in re-epithelialization of laser-wounded renal tubular cell monolayers and deoxycholate- 
injured porcine ileal mucosa $[183,184]$. It is known that constitutive and iNOS activity is present in the intestinal epithelia of several species, thus facilitating the protective effects of NO donors such as arginine and citrulline $[15,182]$. Reports indicated that arginine and citrulline were involved in decreasing inulin flux across hypoxic monolayers and qualitatively preserved tight junction proteins [181]. Taken together, these findings showed that arginine and citrulline, via a mechanism dependent on NO donation, protects the intestinal epithelial integrity. Inflammation in porcine intestinal tract affects absorption of nutrients, reduces growth performance, and also decreases immunity, leading to pathogenic microorganisms infections in animals [185]. Intestinal porcine enterocyte cells-jejunum2 (IPEC-J2) are normal cells derived from the jejunal epithelial cells of the piglet with good biological characteristics of intestinal epithelial cells [186,187]. Lipopolysaccharide (LPS), an endotoxin, and other related toxic substances such as aflatoxin, can trigger inflammatory response in intestinal cells such as IPEC-J2 by stimulating the expression of inflammatory cytokines including IL-6 and IL-8 [188]. Quercetin possesses anti-inflammatory potential that can be expressed on different cell types, both in animal and human models $[189,190]$. Chen et al. [191] conducted an in vitro experiment to determine whether or not quercetin had the potential to inhibit inflammation in the small intestine of pigs by initially pretreating IPEC-J2 with quercetin, and then LPS. It was confirmed that pre-treatment of quercetin showed protective effects on the intestinal porcine enterocyte cells and inhibited porcine intestinal inflammation induced by LPS. Quercetin promotes mast cell stability, gastrointestinal cytoprotection, and also modulates gut immunity $[190,192]$.

Therefore, since quercetin plays several biological roles just as L-citrulline with regards to promoting gut health, we propose that there would exist synergistic, beneficial interactions when these two bio-active substances are utilized together, to promote gut health. Thus, a citrulline + quercetin combination may assist in ameliorating intestinal disorders such as IBD pathogenesis, via restoring the intestinal host-microbiota relationship, immunological homeostasis, modulation of pro-and anti-inflammatory cytokines milieu, and enhancing the antioxidant properties of intestinal tissues. Studies have also explored the effectiveness of using quercetin or citrulline in combination with other components, mainly to harness their beneficial effects. Supplementation of citrulline with Lactobacillus helveticus (a bacteria strain that can catabolize arginine/citrulline for cell growth) exhibited synergistic effects in promoting NO production and improving intestinal epithelial barrier functions [98]. In a study investigating the effects of magnolol (an active ingredient utilized in traditional Chinese medicine) in L-arginine-induced gastrointestinal motility disorder, it was reported that magnolol alleviated gut disorder via reducing NO production, and its relaxing properties on GIT [193]. Another study employing the combination of dasatinib and quercetin as senolytic drugs in aged mice revealed that their long-term treatment reduced senescence cells, reduced inflammatory markers, and altered metabolic signatures in the intestines, thus improving gut health [194]. Additionally, studies have combined polyphenols such as resveratrol and quercetin widely for their health benefits, and their role in modulating the gut microbial ecosystem [2,28]. Combination of rice bran and quercetin altered gut microbiome composition and metabolites, such that there was a significant shift to enrich the proliferation of beneficial bacteria, while the population of opportunistic pathogens in the gut was reduced [195]. Quercetin and catechin combination was reported as a potential therapy for alleviating excessive adipose tissue inflammation, improving metabolic parameters related to insulin sensitivity, and regulating cell redox status to exert anti-inflammatory actions [196]. In addition, quercetin elicited synergistic roles together with vitamin $\mathrm{E}$ to promote anti-inflammation, anti-apoptosis, and immunity in aged hens $[197,198]$.

Presently, studies investigating the interaction between citrulline and quercetin are unavailable, and this present review intends to direct research focus towards their potentials in promoting gut health. Therefore, since both citrulline and quercetin are natural bioactive compounds found majorly in a variety of foods, such as citrus, vegetables, and beverages, we suggest the possible beneficial effects of these two metabolites, owing to several studies 
elucidating on their diverse biological properties, including anti-inflammatory, antioxidant, and gut-modulating effects, as well as other bioactivities.

\section{Knowledge Gaps and Future Perspectives}

Several studies have revealed citrulline as an efficacious substance with antiinflammatory, anti-oxidative properties, and a high capability to mediate gut functions. The ability of citrulline to serve as a potent arginine precursor allows for its potential application under conditions of arginine deficiency, such as in inflammatory states [9]. However, most of the studies conducted on citrulline's effects have been linked to its ability as an arginine precursor and NO-dependent mechanisms. Thus, there is a paucity of research on the direct effects of citrulline and interactions that may be involved, warranting further investigations.

With citrulline's role as a gut biomarker, and a functional metabolite of the gut, as well as the numerous reports supporting quercetin's role in gut microbiota modulation, we suggest that synergistic effects may exist when these two substances are co-utilized, considering they have similar attributes of antioxidative, anti-inflammatory, and immuneregulatory roles in the gut, especially under pathophysiological conditions. Importantly, the effectiveness of quercetin in alleviating colitis and IBD treatment is impeded due to its rapid metabolism and primary absorption in the upper gastrointestinal tract, as such limiting its transit and absorption in the lower gastrointestinal tract [199]. This problem is counteracted by supplying quercetin in its glycosylated form, commonly as rutin, which allows for passage through the epithelial cells, and conversion by the gut microbiota to derive the bioactive effects of quercetin [199]. Moreover, in the gut, citrulline is easily absorbed by the gut from the enterocytes lumen such that oral supplementation with citrulline is more efficient than with arginine supplementation to supply arginine [37]. An interesting discovery would be whether citrulline can interact with quercetin to facilitate its absorption in the gut or otherwise. To the best of our knowledge, there are currently no studies that have examined the mutual effects of citrulline and quercetin on gut functions, and the primary aim of this review is to elucidate the benefits of each bioactive substance, while drawing attention to the potential synergistic effects that could be derived when co-utilized. Therefore, investigations to uncover their areas of synergy and antagonism are warranted, especially considering their bioavailability from various plant sources. Prospective studies are necessary to assess the specificity and sensitivity of these dual supplements as possible modulators of intestinal inflammation. Further, it would be interesting to unveil other biological roles for which they may be utilized (apart from the areas covered in this review), during health and pathological states. Furthermore, gut microbiota studies have been considered the novel approach for understanding gut health problems, and thus, the possible benefits of citrulline and quercetin for gut health should be explored through microbiome evaluation, and the association of the omics analysis at the gene, transcripts, proteins, and metabolite levels, to ascertain the biological effects of citrulline + quercetin in microbiota interactions.

\section{Conclusions}

This review has given a recent account of citrulline and quercetin in modulating the intestinal immunity, redox status, and inflammatory conditions in the gut. Studies have demonstrated both citrulline and quercetin as potent bioactive substances, eliciting various beneficial effects on gut functioning and health. Thus, this comprehensive review outlined the major biological roles played by both citrulline and quercetin on gut integrity and microbial composition, and further elucidated the synergistic roles that would exist in utilizing both citrulline and quercetin in health and disease states. Therefore, citrulline and quercetin co-treatment could provide the next novel therapeutic outlook needed to promote gut functions and host health under pathophysiological states. 
Author Contributions: V.A.U. and F.K.A. conceptualized and drafted the manuscript. M.L., and X.Z., contributed in the literature review; Z.C., and H.L. critically reviewed, edited, and approved the final version of the manuscript. All authors have read and agreed to the published version of the manuscript.

Funding: This work was supported by the National Key Research Program of China (2016YFD0500510), the China Agriculture Research System (CARS-40-K09), the National Natural Science Foundation of China (31772619) and the Key Technology Research and Development Program of Shandong Province (2019JZZY020602).

Conflicts of Interest: The authors declare no conflict of interest.

\section{References}

1. Briskey, D.; Tucker, P.S.; Johnson, D.W.; Coombes, J.S. Microbiota and the nitrogen cycle: Implications in the development and progression of CVD and CKD. Nitric Oxide 2016, 57, 64-70. [CrossRef] [PubMed]

2. Zhao, L.; Zhang, Q.; Ma, W.; Tian, F.; Shen, H.; Zhou, M. A combination of quercetin and resveratrol reduces obesity in high-fat diet-fed rats by modulation of gut microbiota. Food Funct. 2017, 8, 4644-4656. [CrossRef] [PubMed]

3. Singh, R.; Chandrashekharappa, S.; Bodduluri, S.R.; Baby, B.V.; Hegde, B.; Kotla, N.G.; Hiwale, A.A.; Saiyed, T.; Patel, P.; Jala, V.R.; et al. Enhancement of the gut barrier integrity by a microbial metabolite through the Nrf2 pathway. Nat. Commun. 2019, 10, 89. [CrossRef] [PubMed]

4. Gao, J.; Xu, K.; Liu, H.; Liu, G.; Bai, M.; Peng, C.; Li, T.; Yin, Y. Impact of the Gut Microbiota on Intestinal Immunity Mediated by Tryptophan Metabolism. Front. Cell. Infect. Microbiol. 2018, 8, 13. [CrossRef]

5. Bortoluzzi, C.; Rochell, S.J.; Applegate, T.J. Threonine, arginine, and glutamine: Influences on intestinal physiology, immunology, and microbiology in broilers. Poult. Sci. 2018, 97, 937-945. [CrossRef]

6. Lynch, S.V.; Pedersen, O. The Human Intestinal Microbiome in Health and Disease. N. Engl. J. Med. 2016, 375, 2369-2379. [CrossRef]

7. Levy, M.; Kolodziejczyk, A.A.; Thaiss, C.A.; Elinav, E. Dysbiosis and the immune system. Nat. Rev. Immunol. 2017, 17, 219-232. [CrossRef]

8. Boudry, G.; Le Huërou-Luron, I.; Michel, C. Dietary Protein and Colonic Microbiota-The Molecular Nutrition of Amino Acids and Proteins; Academic Press: Cambridge, MA, USA, 2016; pp. 207-220.

9. Cynober, L.; Moinard, C.; De Bandt, J.P. The 2009 ESPEN Sir David Cuthbertson. Citrulline: A new major signaling molecule or just another player in the pharmaconutrition game? Clin. Nutr. 2010, 29, 545-551. [CrossRef]

10. Breuillard, C.; Cynober, L.; Moinard, C. Citrulline and nitrogen homeostasis: An overview. Amino Acids 2015, 47, 685-691. [CrossRef]

11. Allerton, T.D.; Proctor, D.N.; Stephens, J.M.; Dugas, T.R.; Spielmann, G.; Irving, B.A. 1-Citrulline Supplementation: Impact on Cardiometabolic Health. Nutrients 2018, 10, 921. [CrossRef]

12. Curis, E.; Nicolis, I.; Moinard, C.; Osowska, S.; Zerrouk, N.; Benazeth, S.; Cynober, L. Almost all about citrulline in mammals. Amino Acids 2005, 29, 177-205. [CrossRef]

13. Kaore, S.N.; Kaore, N.M. Citrulline: Pharmacological Perspectives and Role as a Biomarker in Diseases and Toxicities. In Biomarkers in Toxicology; Gupta, R., Ed.; Academic Press: Cambridge, MA, USA, 2014; pp. 883-905.

14. Lange, S.M.; McKell, M.C.; Schmidt, S.M.; Zhao, J.; Crowther, R.R.; Green, L.C.; Bricker, R.L.; Arnett, E.; Köhler, S.E.; Schlesinger, L.S.; et al. L-Arginine Synthesis from L-Citrulline in Myeloid Cells Drives Host Defense against Mycobacteria In Vivo. J. Immunol. 2019, 202, 1747. [CrossRef]

15. Schwedhelm, E.; Maas, R.; Freese, R.; Jung, D.; Lukacs, Z.; Jambrecina, A.; Spickler, W.; Schulze, F.; Böger, R.H. Pharmacokinetic and pharmacodynamic properties of oral L-citrulline and L-arginine: Impact on nitric oxide metabolism. Br. J. Clin. Pharmacol. 2008, 65, 51-59. [CrossRef]

16. Dey, N.; Bhattacharjee, S. Accumulation of Polyphenolic Compounds and Osmolytes under Dehydration Stress and Their Implication in Redox Regulation in Four Indigenous Aromatic Rice Cultivars. Rice Sci. 2020, 27, 329-344. [CrossRef]

17. Jeppesen, P.B.; Gabe, S.M.; Seidner, D.L.; Lee, H.M.; Olivier, C. Citrulline correlations in short bowel syndrome-intestinal failure by patient stratification: Analysis of 24 weeks of teduglutide treatment from a randomized controlled study. Clin. Nutr. 2020, 39, 2479-2486. [CrossRef]

18. Jirka, A.; Layec, S.; Picot, D.; Bernon-Ferreira, S.; Grasset, N.; Flet, L.; Thibault, R.; Darmaun, D. Effect of oral citrulline supplementation on whole body protein metabolism in adult patients with short bowel syndrome: A pilot, randomized, double-blind, cross-over study. Clin. Nutr. 2019, 38, 2599-2606. [CrossRef]

19. Liu, Y.; Tian, X.; Gou, L.; Fu, X.; Li, S.; Lan, N.; Yin, X. Protective effect of l-citrulline against ethanol-induced gastric ulcer in rats. Environ. Toxicol. Pharmacol. 2012, 34, 280-287. [CrossRef]

20. Ioannou, H.P.; Diamanti, E.; Piretzi, K.; Drossou-Agakidou, V.; Augoustides-Savvopoulou, P. Plasma citrulline levels in preterm neonates with necrotizing enterocolitis. Early Hum. Dev. 2012, 88, 563-566. [CrossRef]

21. Moco, S.; Martin, F.P.; Rezzi, S. Metabolomics view on gut microbiome modulation by polyphenol-rich foods. J. Proteome Res. 2012, 11, 4781-4790. [CrossRef] 
22. Shu, G.; Kong, F.; Xu, D.; Yin, L.; He, C.; Lin, J.; Fu, H.; Wang, K.; Tian, Y.; Zhao, X. Bamboo leaf flavone changed the community of cecum microbiota and improved the immune function in broilers. Sci. Rep. 2020, 10, 12324. [CrossRef]

23. Romero, M.J.; Platt, D.H.; Caldwell, R.B.; Caldwell, R.W. Therapeutic use of citrulline in cardiovascular disease. Cardiovasc. Drug Rev. 2006, 24, 275-290. [CrossRef]

24. Laurentius, A.; Wikanendra, G.B.; Cong, T.H.; Arozal, W. L-citrulline as Alternative Pharmacological Substance in Protecting Against Cardiovascular Disease. Pharm. Sci. Res. 2018, 5, 72-80.

25. Joshi, V.; Joshi, M.; Silwal, D.; Noonan, K.; Rodriguez, S.; Penalosa, A. Systematized biosynthesis and catabolism regulate citrulline accumulation in watermelon. Phytochemistry 2019, 162, 129-140. [CrossRef]

26. Yao, L.; Yao, J.; Han, C.; Yang, J.; Chaudhry, M.T.; Wang, S.; Liu, H.; Yin, Y. Quercetin, Inflammation and Immunity. Nutrients 2016, $8,167$.

27. Ross, J.A.; Kasum, C.M. Dietary flavonoids: Bioavailability, metabolic effects, and safety. Ann. Rev. Nutr. 2002, 22, 19-34. [CrossRef]

28. Etxeberria, U.; Arias, N.; Boqué, N.; Macarulla, M.T.; Portillo, M.P.; Martínez, J.A.; Milagro, F.I. Reshaping faecal gut microbiota composition by the intake of trans-resveratrol and quercetin in high-fat sucrose diet-fed rats. J. Nutr. Biochem. 2015, 26, 651-660. [CrossRef]

29. Padayachee, A.; Day, L.; Howell, K.; Gidley, M.J. Complexity and health functionality of plant cell wall fibers from fruits and vegetables. Crit. Rev. Food Sci. Nutr. 2017, 57, 59-81. [CrossRef]

30. Marcolin, E.; San-Miguel, B.; Vallejo, D.; Tieppo, J.; Marroni, N.; Gonzalez-Gallego, J.; Tuñón, M.J. Quercetin Treatment Ameliorates Inflammation and Fibrosis in Mice with Nonalcoholic Steatohepatitis. J. Nutr. 2012, 142, 1821-1828. [CrossRef]

31. Davis, J.M.; Murphy, E.A.; Carmichael, M.D. Effects of the Dietary Flavonoid Quercetin Upon Performance and Health. Curr. Sports Med. Rep. 2009, 8, 206-213. [CrossRef]

32. Ulusoy, H.G.; Sanlier, N. A minireview of quercetin: From its metabolism to possible mechanisms of its biological activities. Crit. Rev. Food. Sci. Nutr. 2020, 60, 3290-3303. [CrossRef]

33. Frank, K.; Patel, K.; Lopez, G. Citrulline Research Analysis. 2018. Available online: https://examine.com/supplements/ citrulline/research/ (accessed on 24 April 2021).

34. Cuzzocrea, S.; Salvemini, D. Molecular mechanisms involved in the reciprocal regulation of cyclooxygenase and nitric oxide synthase enzymes. Kidney Int. 2007, 71, 290-297. [CrossRef] [PubMed]

35. Guslandi, M. Nitric oxide and inflammatory bowel diseases. Eur. J. Clin. Investig. 1998, 28, 904-907. [CrossRef] [PubMed]

36. Crenn, P.; Messing, B.; Cynober, L. Citrulline as a biomarker of intestinal failure due to enterocyte mass reduction. Clin. Nutr. 2008, 27, 328-339. [CrossRef] [PubMed]

37. Curis, E.; Crenn, P.; Cynober, L. Citrulline and the gut. Curr. Opin. Clin. Nutr. Metab. Care 2007, 10, 620-626. [CrossRef]

38. Wu, G.; Bazer, F.W.; Cudd, T.A.; Jobgen, W.S.; Kim, S.W.; Lassala, A.; Li, P.; Matis, J.H.; Meininger, C.J.; Spencer, T.E. Pharmacokinetics and Safety of Arginine Supplementation in Animals. J. Nutr. 2007, 137, 1673S-1680S. [CrossRef]

39. Wu, G. Intestinal mucosal amino acid catabolism. J. Nutr. 1998, 128, 1249-1252. [CrossRef]

40. Baker, D.H. Comparative nutrition and metabolism: Explication of open questions with emphasis on protein and amino acids. Proc. Natl. Acad. Sci. USA 2005, 102, 17897-17902. [CrossRef]

41. Saitoh, W.; Takada, S.; Hirao, J.; Shirai, M.; Iguchi, T.; Tsuji, M.; Nishiya, T.; Mori, K. Plasma citrulline is a sensitive safety biomarker for small intestinal injury in rats. Toxicol. Lett. 2018, 295, 416-423. [CrossRef]

42. Agarwal, U.; Didelija, I.C.; Yuan, Y.; Wang, X.; Marini, J.C. Supplemental citrulline is more efficient than arginine in increasing systemic arginine availability in mice. J. Nutr. 2017, 147, 596-602. [CrossRef]

43. Uyanga, V.A.; Jiao, H.; Zhao, J.; Wang, X.; Lin, H. Dietary L-citrulline supplementation modulates nitric oxide synthesis and anti-oxidant status of laying hens during summer season. J. Anim. Sci. Biotechnol. 2020, 11, 103. [CrossRef]

44. Moinard, C.; Nicolis, I.; Neveux, N.; Darquy, S.; Benazeth, S.; Cynober, L. Dose-ranging effects of citrulline administration on plasma amino acids and hormonal patterns in healthy subjects: The Citrudose pharmacokinetic study. Br. J. Nutr. 2008, 99, 855-862. [CrossRef]

45. Wijnands, K.A.; Meesters, D.M.; van Barneveld, K.W.; Visschers, R.G.; Briede, J.J.; Vandendriessche, B.; van Eijk, H.M.; Bessems, B.A.; van den Hoven, N.; von Wintersdorff, C.J.; et al. Citrulline Supplementation Improves Organ Perfusion and Arginine Availability under Conditions with Enhanced Arginase Activity. Nutrients 2015, 7, 5217-5238. [CrossRef]

46. Wijnands, K.A.; Vink, H.; Briede, J.J.; van Faassen, E.E.; Lamers, W.H.; Buurman, W.A.; Poeze, M. Citrulline a more suitable substrate than arginine to restore NO production and the microcirculation during endotoxemia. PLoS ONE 2012, 7, e37439. [CrossRef]

47. Morita, M.; Hayashi, T.; Ochiai, M.; Maeda, M.; Yamaguchi, T.; Ina, K.; Kuzuya, M. Oral supplementation with a combination of L-citrulline and L-arginine rapidly increases plasma L-arginine concentration and enhances NO bioavailability. Biochem. Biophys. Res. Commun. 2014, 454, 53-57. [CrossRef]

48. Crozier, A.; Del Rio, D.; Clifford, M.N. Bioavailability of dietary flavonoids and phenolic compounds. Mol. Asp. Med. 2010, 31, 446-467. [CrossRef] [PubMed]

49. Del Rio, D.; Rodriguez-Mateos, A.; Spencer, J.P.; Tognolini, M.; Borges, G.; Crozier, A. Dietary (poly)phenolics in human health: Structures, bioavailability, and evidence of protective effects against chronic diseases. Antioxid. Redox Signal. 2013, 18, 1818-1892. [CrossRef] 
50. Crespy, V.; Morand, C.; Besson, C.; Manach, C.; Demigne, C.; Remesy, C. Quercetin, but not its glycosides, is absorbed from the rat stomach. J. Agric. Food Chem. 2002, 50, 618-621. [CrossRef]

51. Ader, P.; Wessmann, A.; Wolffram, S. Bioavailability and metabolism of the flavonol quercetin in the pig. Free Radic. Biol. Med. 2000, 28, 1056-1067. [CrossRef]

52. Erlund, I.; Kosonen, T.; Alfthan, G.; Mäenpää, J.; Perttunen, K.; Kenraali, J.; Parantainen, J.; Aro, A. Pharmacokinetics of quercetin from quercetin aglycone and rutin in healthy volunteers. Eur. J. Clin. Pharmacol. 2000, 56, 545-553. [CrossRef]

53. Graefe, E.U.; Derendorf, H.; Veit, M. Pharmacokinetics and bioavailability of the flavonol quercetin in humans. Int. J. Clin. Pharmacol. Ther. 1999, 37, 219-233.

54. Azuma, K.; Ippoushi, K.; Ito, H.; Higashio, H.; Terao, J. Combination of lipids and emulsifiers enhances the absorption of orally administered quercetin in rats. J. Agric. Food Chem. 2002, 50, 1706-1712. [CrossRef] [PubMed]

55. Smith, A.J.; Kavuru, P.; Wojtas, L.; Zaworotko, M.J.; Shytle, R.D. Cocrystals of quercetin with improved solubility and oral bioavailability. Mol. Pharm. 2011, 8, 1867-1876. [CrossRef] [PubMed]

56. Day, A.J.; Cañada, F.J.; Díaz, J.C.; Kroon, P.A.; McLauchlan, R.; Faulds, C.B.; Plumb, G.W.; Morgan, M.R.; Williamson, G. Dietary flavonoid and isoflavone glycosides are hydrolysed by the lactase site of lactase phlorizin hydrolase. FEBS Lett. 2000, 468, 166-170. [CrossRef]

57. Hollman, P.C.; de Vries, J.H.; van Leeuwen, S.D.; Mengelers, M.J.; Katan, M.B. Absorption of dietary quercetin glycosides and quercetin in healthy ileostomy volunteers. Am. J. Clin. Nutr. 1995, 62, 1276-1282. [CrossRef]

58. Hollman, P.C.; van Trijp, J.M.; Mengelers, M.J.; de Vries, J.H.; Katan, M.B. Bioavailability of the dietary antioxidant flavonol quercetin in man. Cancer Lett. 1997, 114, 139-140. [CrossRef]

59. Hollman, P.C.; vd Gaag, M.; Mengelers, M.J.; van Trijp, J.M.; de Vries, J.H.; Katan, M.B. Absorption and disposition kinetics of the dietary antioxidant quercetin in man. Free Radic. Biol. Med. 1996, 21, 703-707. [CrossRef]

60. Arts, I.C.; Sesink, A.L.; Faassen-Peters, M.; Hollman, P.C. The type of sugar moiety is a major determinant of the small intestinal uptake and subsequent biliary excretion of dietary quercetin glycosides. Br. J. Nutr. 2004, 91, 841-847. [CrossRef]

61. Cermak, R.; Landgraf, S.; Wolffram, S. The bioavailability of quercetin in pigs depends on the glycoside moiety and on dietary factors. J. Nutr. 2003, 133, 2802-2807. [CrossRef]

62. Reinboth, M.; Wolffram, S.; Abraham, G.; Ungemach, F.R.; Cermak, R. Oral bioavailability of quercetin from different quercetin glycosides in dogs. Br. J. Nutr. 2010, 104, 198-203. [CrossRef]

63. Russo, M.; Spagnuolo, C.; Tedesco, I.; Bilotto, S.; Russo, G.L. The flavonoid quercetin in disease prevention and therapy: Facts and fancies. Biochem. Pharmacol. 2012, 83, 6-15. [CrossRef]

64. Dragoni, S.; Gee, J.; Bennett, R.; Valoti, M.; Sgaragli, G. Red wine alcohol promotes quercetin absorption and directs its metabolism towards isorhamnetin and tamarixetin in rat intestine in vitro. Br. J. Pharmacol. 2006, 147, 765-771. [CrossRef]

65. Matsukawa, N.; Matsumoto, M.; Shinoki, A.; Hagio, M.; Inoue, R.; Hara, H. Nondigestible saccharides suppress the bacterial degradation of quercetin aglycone in the large intestine and enhance the bioavailability of quercetin glucoside in rats. J. Agric. Food Chem. 2009, 57, 9462-9468. [CrossRef]

66. Guo, Y.; Mahm, E.; Davis, C.G.; Jalili, T.; Ferruzzi, M.G.; Chun, O.K.; Bruno, R.S. Dietary fat increases quercetin bioavailability in overweight adults. Mol. Nutr. Food Res. 2013, 57, 896-905. [CrossRef]

67. Lesser, S.; Cermak, R.; Wolffram, S. Bioavailability of quercetin in pigs is influenced by the dietary fat content. J. Nutr. 2004, 134, 1508-1511. [CrossRef]

68. Vacek, J.; Papoušková, B.; Kosina, P.; Vrba, J.; Křen, V.; Ulrichová, J. Biotransformation of flavonols and taxifolin in hepatocyte in vitro systems as determined by liquid chromatography with various stationary phases and electrospray ionization-quadrupole time-of-flight mass spectrometry. J. Chromatogr. B 2012, 899, 109-115. [CrossRef]

69. Cermak, R.; Wolffram, S. The potential of flavonoids to influence drug metabolism and pharmacokinetics by local gastrointestinal mechanisms. Curr. Drug Metab. 2006, 7, 729-744. [CrossRef]

70. Galindo, P.; Rodriguez-Gómez, I.; González-Manzano, S.; Dueñas, M.; Jiménez, R.; Menéndez, C.; Vargas, F.; Tamargo, J.; Santos-Buelga, C.; Pérez-Vizcaíno, F.; et al. Glucuronidated quercetin lowers blood pressure in spontaneously hypertensive rats via deconjugation. PLoS ONE 2012, 7, e32673. [CrossRef]

71. Menendez, C.; Dueñas, M.; Galindo, P.; González-Manzano, S.; Jimenez, R.; Moreno, L.; Zarzuelo, M.J.; Rodríguez-Gómez, I.; Duarte, J.; Santos-Buelga, C.; et al. Vascular deconjugation of quercetin glucuronide: The flavonoid paradox revealed? Mol. Nutr. Food Res. 2011, 55, 1780-1790. [CrossRef]

72. Perez, A.; Gonzalez-Manzano, S.; Jimenez, R.; Perez-Abud, R.; Haro, J.M.; Osuna, A.; Santos-Buelga, C.; Duarte, J.; Perez-Vizcaino, F. The flavonoid quercetin induces acute vasodilator effects in healthy volunteers: Correlation with beta-glucuronidase activity. Pharmacol. Res. 2014, 89, 11-18. [CrossRef]

73. Shimoi, K.; Saka, N.; Nozawa, R.; Sato, M.; Amano, I.; Nakayama, T.; Kinae, N. Deglucuronidation of a flavonoid, luteolin monoglucuronide, during inflammation. Drug Metab. Dispos. 2001, 29, 1521-1524.

74. Araújo, K.C.; Costa, E.M.D.M.; Pazini, F.; Valadares, M.C.; de Oliveira, V. Bioconversion of quercetin and rutin and the cytotoxicity activities of the transformed products. Food Chem. Toxicol. 2013, 51, 93-96. [CrossRef]

75. Beekmann, K.; Actis-Goretta, L.; van Bladeren, P.J.; Dionisi, F.; Destaillats, F.; Rietjens, I.M. A state-of-the-art overview of the effect of metabolic conjugation on the biological activity of flavonoids. Food Funct. 2012, 3, 1008-1018. [CrossRef] 
76. Lodi, F.; Jimenez, R.; Moreno, L.; Kroon, P.A.; Needs, P.W.; Hughes, D.A.; Santos-Buelga, C.; Gonzalez-Paramas, A.; Cogolludo, A.; Lopez-Sepulveda, R.; et al. Glucuronidated and sulfated metabolites of the flavonoid quercetin prevent endothelial dysfunction but lack direct vasorelaxant effects in rat aorta. Atherosclerosis 2009, 204, 34-39. [CrossRef]

77. Tribolo, S.; Lodi, F.; Connor, C.; Suri, S.; Wilson, V.G.; Taylor, M.A.; Needs, P.W.; Kroon, P.A.; Hughes, D.A. Comparative effects of quercetin and its predominant human metabolites on adhesion molecule expression in activated human vascular endothelial cells. Atherosclerosis 2008, 197, 50-56. [CrossRef]

78. Williamson, G.; Barron, D.; Shimoi, K.; Terao, J. In vitro biological properties of flavonoid conjugates found in vivo. Free Radic. Res. 2005, 39, 457-469. [CrossRef]

79. Almeida, A.F.; Borge, G.I.A.; Piskula, M. Bioavailability of Quercetin in Humans with a Focus on Interindividual Variation. Compr. Rev. Food Sci. Food Saf. 2018, 17, 714-731. [CrossRef]

80. Cermak, R.; Breves, G.M. In vitro degradation of the flavonol quercetin and of quercetin glycosides in the porcine hindgut. Arch. Anim. Nutr. 2006, 60, 180-189. [CrossRef]

81. Sokolová, R.; Ramešová, Š.; Degano, I.; Hromadová, M.; Gál, M.; Žabka, J. The oxidation of natural flavonoid quercetin. Chem. Commun. 2012, 48, 3433-3435. [CrossRef]

82. Ramešová, S.; Sokolová, R.; Degano, I.; Bulíčková, J.; Zabka, J.; Gál, M. On the stability of the bioactive flavonoids quercetin and luteolin under oxygen-free conditions. Anal. Bioanal. Chem. 2012, 402, 975-982. [CrossRef]

83. Walle, T. Absorption and metabolism of flavonoids. Free Radic. Biol. Med. 2004, 36, 829-837. [CrossRef]

84. Walle, T.; Walle, U.K.; Halushka, P.V. Carbon dioxide is the major metabolite of quercetin in humans. J. Nutr. 2001, 131, 2648-2652. [CrossRef] [PubMed]

85. Celi, P.; Cowieson, A.J.; Fru-Nji, F.; Steinert, R.E.; Kluenter, A.M.; Verlhac, V. Gastrointestinal functionality in animal nutrition and health: New opportunities for sustainable animal production. Anim. Feed Sci. Technol. 2017, 234, 88-100. [CrossRef]

86. Davila, A.M.; Blachie, R.F.; Gotteland, M.; Andriamihaja, M.; Benetti, P.H.; Sanz, Y.; Tomé, D. Intestinal luminal nitrogen metabolism: Role of the gut microbiota and consequences for the host. Pharmacol. Res. 2013, 68, 95-107. [CrossRef] [PubMed]

87. Teixeira, T.F.; Collado, M.C.; Ferreira, C.L.; Bressan, J.; Peluzio Mdo, C. Potential mechanisms for the emerging link between obesity and increased intestinal permeability. Nutr. Res. 2012, 32, 637-647. [CrossRef]

88. Banerjee, A. Gastrointestinal Toxicity Biomarkers. In Biomarkers in Toxicology; Academic Press: Cambridge, MA, USA, 2014; pp. 269-277.

89. Grimaldi, D.; Guivarch, E.; Neveux, N.; Fichet, J.; Pene, F.; Marx, J.S.; Chiche, J.D.; Cynober, L.; Mira, J.P.; Cariou, A. Markers of intestinal injury are associated with endotoxemia in successfully resuscitated patients. Resuscitation 2013, 84, 60-65. [CrossRef]

90. Derikx, J.P.M.; Luyer, M.D.P.; Heineman, E.; Buurman, W.A. Non-invasive markers of gut wall integrity in health and disease. World J. Gastroenterol. 2010, 16, 5272-5279. [CrossRef]

91. Papadia, C.; Dhaliwal, W.; Kelly, P.; Corazza, G.R.; Franzè, A.; Di Sabatino, A. Plasma citrulline as a quantitative biomarker of HIV-associated duodenalmucosal damage in a tropical enteropathy population. Clin. Nutr. 2010, 29, 795-800. [CrossRef]

92. Jäckel, S.; Emde, B.; Lai, V.; Weigt, S.; Hanschke, B.; Kasper, L. L-Citrulline as translational safety biomarker for the small intestine-An update. J. Pharmacol. Toxicol. Methods 2020, 105, 106863. [CrossRef]

93. Shen, L.J.; Guan, Y.Y.; Wu, X.P.; Wang, Q.; Wang, L.; Xiao, T.; Wu, H.R.; Wang, J.G. Serum citrulline as a diagnostic marker of sepsis-induced intestinal dysfunction. Clin. Res. Hepatol. Gastroenterol. 2015, 39, 230-236. [CrossRef]

94. Sellmann, C.; Jin, C.J.; Engstler, A.J.; De Bandt, J.P.; Bergheim, I. Oral citrulline supplementation protects female mice from the development of non-alcoholic fatty liver disease (NAFLD). Eur. J. Nutr. 2017, 56, 2519-2527. [CrossRef]

95. Elmassry, M.M.; Zayed, A.; Farag, M.A. Gut homeostasis and microbiota under attack: Impact of the different types of food contaminants on gut health. Crit. Rev. Food Sci. Nutr. 2020, 2020, 1-26. [CrossRef]

96. Mouna, H.; Manichanh, C.; Schoenenberger, A.; Pascal, V.; Florence, L.; Cournède, N.; Doré, J.; Melchior, J.C. Altered host-gut microbes symbiosis in severely malnourished anorexia nervosa (AN) patients undergoing enteral nutrition: An explicative factor of functional intestinal disorders? Clin. Nutr. 2018, 38, 2304-2310. [CrossRef]

97. Diling, C.; Yinrui, G.; Longkai, Q.; Xiaocui, T.; Yadi, L.; Jiaxin, F. Metabolic regulation of Ganoderma lucidum extracts in high sugar and fat diet-induced obese mice by regulating the gut-brain axis. J. Funct. Foods 2020, 65, 103639. [CrossRef]

98. Ho, S.W.; El-Nezami, H.; Shah, N.P. Effects of supplementation of citrulline and Lactobacillus helveticus ASCC 511 on intestinal epithelial cell integrity. J. Funct. Foods 2020, 64, 103571. [CrossRef]

99. Moinard, C.; Walrand, S.; Boirie, Y.; Cynober, L. Use of Citrulline for the Treatment of Conditions Linked to an Increase in Protein Carbonylation. 2007. Available online: http:/ / europepmc.org/article/PAT/EP2136777 (accessed on 10 March 2021).

100. Becraft, A.R.; Sturm, M.L.; Mendez, R.L.; Park, S.H.; Lee, S.I.; Shay, N.F. Intake of Watermelon or Its Byproducts Alters Glucose Metabolism, the Microbiome, and Hepatic Proinflammatory Metabolites in High-Fat-Fed Male C57BL/6 J Mice. J. Nutr. 2020, 150, 434-442. [CrossRef]

101. Nguyen, T.L.; Chun, W.K.; Kim, A.; Kim, N.; Roh, H.J.; Lee, Y.; Yi, M.; Kim, S.; Park, C.; Kim, D.H. Dietary Probiotic Effect of Lactococcus lactis WFLU12 on Low-Molecular-Weight Metabolites and Growth of Olive Flounder (Paralichythys olivaceus). Front. Microbiol. 2018, 9, 2059. [CrossRef]

102. Chen, R.Q.; Liao, C.B.; Guo, Q.; Wu, L.R.; Zhang, L.; Wang, X.F. Combined systems pharmacology and fecal metabonomics to study the biomarkers and therapeutic mechanism of type 2 diabetic nephropathy treated with Astragalus and Leech. RSC Adv. 2018, 8, 27448-27463. [CrossRef] 
103. Adamovsky, O.; Buerger, A.N.; Vespalcova, H.; Sohag, S.R.; Hanlon, A.T.; Ginn, P.E.; Craft, S.L.; Budinska, E.; Persico, M. et al. Evaluation of Microbiome-Host Relationships in the Zebrafish Gastrointestinal System Reveals Adaptive Immunity Is a Target of Bis(2-ethylhexyl) Phthalate (DEHP) Exposure. Environ. Sci. Technol. 2020, 54, 5719-5728. [CrossRef]

104. Jackel, S.; Pipp, F.C.; Emde, B.; Weigt, S.; Vigna, E.; Hanschke, B.; Kasper, L.; Siddharta, A.; Hellmann, J.; Czasch, S.; et al. L-citrulline: A preclinical safety biomarker for the small intestine in rats and dogs in repeat dose toxicity studies. J. Pharmacol. Toxicol. Methods 2021, 110, 107110. [CrossRef]

105. Authier, S.; Tang, H.-M.; Abtout, S.; Ascah, A.; Pouliot, M.; Bujold, K.; Troncy, E.; Pugsley, M.K.; Forster, R. Gastroinstestinal motility: Motility and motor migrating complex (mmc) evaluations in rats, dogs and non-human primates. J. Pharmacol. Toxicol. Methods 2016, 81, 389-390. [CrossRef]

106. Feenstra, F.A.; Kuik, S.J.; Derikx, J.P.M.; Heiner-Fokkema, M.R.; Kooi, E.M.W.; Bos, A.F.; Hulscher, J.B.F. Plasma citrulline during the first $48 \mathrm{~h}$ after onset of necrotizing enterocolitis in preterm infants. J. Pediatr. Surg. 2020, 56, 476-482. [CrossRef] [PubMed]

107. Filippi, J.; Rubio, A.; Lasserre, V.; Maccario, J.; Walrand, S.; Neveux, N.; Plenier, S.L.; Hebuterne, X.; Cynober, L.; Moinard, C. Dose-dependent beneficial effects of citrulline supplementation in short bowel syndrome in rats. Nutr. J. 2021, 85, 111118. [CrossRef] [PubMed]

108. Rajcic, D.; Baumann, A.; Hernandez-Arriaga, A.; Brandt, A.; Nier, A.; Jin, C.J.; Sanchez, V.; Jung, F.; Camarinha-Silva, A.; Bergheim, I. Citrulline supplementation attenuates the development of non-alcoholic steatohepatitis in female mice through mechanisms involving intestinal arginase. Redox Biol. 2021, 41, 101879. [CrossRef] [PubMed]

109. Van Wijck, K.; Wijnands, K.A.P.; Meesters, D.M.; Boonen, B.; van Loon, L.J.C.; Buurman, W.A.; Dejong, C.H.C.; Lenaerts, K.; Poeze, M. L-citrulline improves splanchnic perfusion and reduces gut injury during exercise. Med. Sci. Sports Exerc. 2014, 46, 2039-2046. [CrossRef]

110. Batista, M.A.; Nicoli, J.R.; dos Santos Martins, F.; Nogueira Machado, J.A.; Esteves Arantes, R.M.; Pacífico Quirino, I.E. Davisson Correia, M.I.T.; Cardoso, V.N. Pretreatment with citrulline improves gut barrier after intestinal obstruction in mice. J. Parenter. Enter. Nutr. 2012, 36, 69-76. [CrossRef]

111. Najmanová, I.; Pourová, J.; Vopršalová, M.; Pilařová, V.; Semecký, V.; Nováková, L.; Mladěnka, P. Flavonoid metabolite 3-(3hydroxyphenyl)propionic acid formed by human microflora decreases arterial blood pressure in rats. Mol. Nutr. Food Res. 2016, 60, 981-991. [CrossRef]

112. Osowska, S.; Moinard, C.; Loï, C.; Neveux, N.; Cynober, L. Citrulline increases arginine pools and restores nitrogen balance after massive intestinal resection. Gut 2004, 53, 1781. [CrossRef]

113. Gou, L.; Zhang, L.; Yin, C.; Jia, G.; Yin, X.; Zhuang, X.; Xu, X.; Liu, Y. Protective effect of l-citrulline against acute gastric mucosal lesions induced by ischemia-reperfusion in rats. Can. J. Physiol. Pharmacol. 2011, 89, 317-327. [CrossRef]

114. Antunes, M.M.; Leocádio, P.C.L.; Teixeira, L.G.; Leonel, A.J.; Cara, D.C.; Menezes, G.B.; Generoso, S.d.V.; Cardoso, V.N.; AlvarezLeite, J.I.; Correia, M.I.T.D. Pretreatment with L-citrulline positively affects the mucosal architecture and permeability of the small intestine in a murine mucositis model. J. Parenter. Enter. Nutr. 2016, 40, 279-286. [CrossRef]

115. Suzuki, T.; Hara, H. Quercetin enhances intestinal barrier function through the assembly of zonula [corrected] occludens-2, occludin, and claudin-1 and the expression of claudin-4 in Caco-2 cells. J. Nutr. 2009, 139, 965-974. [CrossRef]

116. Valenzano, M.C.; DiGuilio, K.; Mercado, J.; Teter, M.; To, J.; Ferraro, B.; Mixson, B.; Manley, I.; Baker, V.; Moore, B.A.; et al. Remodeling of Tight Junctions and Enhancement of Barrier Integrity of the CACO-2 Intestinal Epithelial Cell Layer by Micronutrients. PLoS ONE 2015, 10, e0133926. [CrossRef]

117. Xue, H.; Xie, W.; Jiang, Z.; Wang, M.; Wang, J.; Zhao, H.; Zhang, X. 3,4-Dihydroxyphenylacetic acid, a microbiota-derived metabolite of quercetin, attenuates acetaminophen (APAP)-induced liver injury through activation of Nrf-2. Xenobiotica 2016, 46, 931-939. [CrossRef]

118. Vissiennon, C.; Nieber, K.; Kelber, O.; Butterweck, V. Route of administration determines the anxiolytic activity of the flavonols kaempferol, quercetin and myricetin-Are they prodrugs? J. Nutr. Biochem. 2012, 23, 733-740. [CrossRef]

119. Kim, H.P.; Mani, I.; Iversen, L.; Ziboh, V.A. Effects of naturally-occurring flavonoids and biflavonoids on epidermal cyclooxygenase and lipoxygenase from guinea-pigs. Prostaglandins Leukot. Essent. Fat. Acids 1998, 58, 17-24. [CrossRef]

120. Shi, T.; Bian, X.; Yao, Z.; Wang, Y.; Gao, W.; Guo, C. Quercetin improves gut dysbiosis in antibiotic-treated mice. Food Funct. 2020, 11, 8003-8013. [CrossRef]

121. Dong, Y.; Lei, J.; Zhang, B. Effects of dietary quercetin on the antioxidative status and cecal microbiota in broiler chickens fed with oxidized oil. Poult. Sci. 2020, 99, 4892-4903. [CrossRef]

122. Chen, T.; Yang, C.S. Biological fates of tea polyphenols and their interactions with microbiota in the gastrointestinal tract: Implications on health effects. Crit. Rev. Food Sci. Nutr. 2020, 60, 2691-2709. [CrossRef]

123. Porras, D.; Nistal, E.; Martínez-Flórez, S.; Pisonero-Vaquero, S.; Olcoz, J.L.; Jover, R.; González-Gallego, J.; García-Mediavilla, M.V.; Sánchez-Campos, S. Protective effect of quercetin on high-fat diet-induced non-alcoholic fatty liver disease in mice is mediated by modulating intestinal microbiota imbalance and related gut-liver axis activation. Free Radic. Biol. Med. 2017, 102, 188-202. [CrossRef]

124. Nie, J.; Zhang, L.; Zhao, G.; Du, X. Quercetin reduces atherosclerotic lesions by altering the gut microbiota and reducing atherogenic lipid metabolites. J. Appl. Microbiol. 2019, 127, 1824-1834. [CrossRef]

125. Lin, R.; Piao, M.; Song, Y. Dietary quercetin increases colonic microbial diversity and attenuates colitis severity in citrobacter rodentium-infected mice. Front. Microbiol. 2019, 10, 1092. [CrossRef] 
126. Sun, L.; Xu, G.; Dong, Y.; Li, M.; Yang, L.; Lu, W. Quercetin protects against lipopolysaccharide-induced intestinal oxidative stress in broiler chickens through activation of nrf2 pathway. Molecules 2020, 25, 1053. [CrossRef]

127. Zou, Y.; Wei, H.K.; Xiang, Q.H.; Wang, J.; Zhou, Y.F.; Peng, J. Protective effect of quercetin on pig intestinal integrity after transport stress is associated with regulation oxidative status and inflammation. J. Vet. Med. Sci. 2016, 78, 1487-1494. [CrossRef]

128. Qin, H.Y.; Zang, K.H.; Zuo, X.; Wu, X.A.; Bian, Z.X. Quercetin attenuates visceral hypersensitivity and 5-hydroxytryptamine availability in postinflammatory irritable bowel syndrome rats: Role of enterochromaffin cells in the colon. J. Med. Food. 2019, 22, 663-671. [CrossRef]

129. Lan, H.; Hong, W.; Qian, D.; Peng, F.; Li, H.; Liang, C.; Du, M.; Gu, J.; Mai, J.; Bai, B.; et al. Quercetin modulates the gut microbiota as well as the metabolome in a rat model of osteoarthritis. Bioengineered 2021, 12, 6240-6250. [CrossRef]

130. Abdel-Latif, M.A.; Elbestawy, A.R.; El-Far, A.H.; Noreldin, A.E.; Emam, M.; Baty, R.S.; Albadrani, G.M.; Abdel-Daim, M.M.; Abd El-Hamid, H.S. Quercetin dietary supplementation advances growth performance, gut microbiota, and intestinal mrna expression genes in broiler chickens. Animals 2021, 11, 2302. [CrossRef]

131. Zhao, L.; Zhu, X.; Xia, M.; Li, J.; Guo, A.-Y.; Zhu, Y.; Yang, X. Quercetin ameliorates gut microbiota dysbiosis that drives hypothalamic damage and hepatic lipogenesis in monosodium glutamate-induced abdominal obesity. Front. Nutr. 2021, 8 , 671353. [CrossRef]

132. Xie, J.; Song, W.; Liang, X.; Zhang, Q.; Shi, Y.; Liu, W.; Shi, X. Protective effect of quercetin on streptozotocin-induced diabetic peripheral neuropathy rats through modulating gut microbiota and reactive oxygen species level. Biomed. Pharmacother. 2020, 127, 110147. [CrossRef]

133. Wan, M.L.Y.; Ling, K.H.; El-Nezami, H.; Wang, M.F. Influence of functional food components on gut health. Crit. Rev. Food Sci. Nutr. 2019, 59, 1927-1936. [CrossRef]

134. Hong, Z.; Piao, M. Effect of quercetin monoglycosides on oxidative stress and gut microbiota diversity in mice with dextran sodium sulphate-induced colitis. BioMed Res. Int. 2018, 2018, 1-7. [CrossRef]

135. Cai, B.; Zhou, M.-H.; Huang, H.-L.; Zhou, A.-C.; Chu, Z.-D.; Huang, X.-D.; Li, C.-W. Protective effects of citrulline supplementation in ulcerative colitis rats. PLOS ONE 2020, 15, e0240883. [CrossRef]

136. Papadia, C.; Osowska, S.; Cynober, L.; Forbes, A. Citrulline in health and disease. Review on human studies. Clin. Nutr. 2018, 37, 1823-1828. [CrossRef] [PubMed]

137. Ouaknine Krief, J.; Helly de Tauriers, P.; Dumenil, C.; Neveux, N.; Dumoulin, J.; Giraud, V.; Labrune, S.; Tisserand, J.; Julie, C.; Emile, J.F.; et al. Role of antibiotic use, plasma citrulline and blood microbiome in advanced non-small cell lung cancer patients treated with nivolumab. J. Immunother. Cancer 2019, 7, 176. [CrossRef] [PubMed]

138. Vande Vyver, M.; Beelen, R.; De Keyser, J.; Nagels, G.; Van Binst, A.M.; Verborgh, C.; D’haeseleer, M. Plasma citrulline levels are increased in patients with multiple sclerosis. J. Neurol. Sci. 2018, 387, 174-178. [CrossRef] [PubMed]

139. Breuillard, C.; Curis, E.; Le Plenier, S.; Cynober, L.; Moinard, C. Nitric oxide production by peritoneal macrophages from aged rats: A short term and direct modulation by citrulline. Biochimie 2017, 133, 66-73. [CrossRef]

140. Lange, S.M.; McKell, M.C.; Schmidt, S.M.; Hossfeld, A.P.; Chaturvedi, V.; Kinder, J.M.; McAlees, J.W.; Lewkowich, I.P.; Way, S.S.; Turner, J.; et al. L-Citrulline metabolism in mice augments $\mathrm{cd} 4^{+} \mathrm{t}$ cell proliferation and cytokine production in vitro, and accumulation in the mycobacteria-infected lung. Front. Immunol. 2017, 8, 1561. [CrossRef]

141. Breuillard, C.; Bonhomme, S.; Couderc, R.; Cynober, L.; De Bandt, J.P. In vitro anti-inflammatory effects of citrulline on peritoneal macrophages in Zucker diabetic fatty rats. Br. J. Nutr. 2015, 113, 120-124. [CrossRef]

142. Lee, Y.C.; Su, Y.T.; Liu, T.Y.; Tsai, C.M.; Chang, C.H.; Yu, H.R. L-arginine and l-citrulline supplementation have different programming effect on regulatory T-cells function of infantile rats. Front. Immunol. 2018, 9, 2911. [CrossRef]

143. Crenn, P.; Neveux, N.; Chevret, S.; Jaffray, P.; Cynober, L.; Melchior, J.C.; Annane, D.; for the COIITSS Study Group. Plasma L-citrulline concentrations and its relationship with inflammation at the onset of septic shock: A pilot study. J. Crit. Care 2014, 29, 315.e1-315.e6. [CrossRef]

144. Azizi, S.; Mahdavi, R.; Vaghef-Mehrabany, E.; Maleki, V.; Karamzad, N.; Ebrahimi-Mameghani, M. Potential roles of Citrulline and watermelon extract on metabolic and inflammatory variables in diabetes mellitus, current evidence and future directions: A systematic review. Clin. Exp. Pharm. Physiol. 2020, 47, 187-198. [CrossRef]

145. Romero, M.J.; Yao, L.; Sridhar, S.; Bhatta, A.; Dou, H.; Ramesh, G.; Brands, M.W.; Pollock, D.M.; Caldwell, R.B.; Cederbaum, S.D.; et al. L-Citrulline protects from kidney damage in type 1 diabetic mice. Front. Immunol. 2013, 4, 480. [CrossRef]

146. Azeredo, R.; Machado, M.; Fontinha, F.; Fernandez-Boo, S.; Conceição, L.E.; Dias, J.; Costas, B. Dietary arginine and citrulline supplementation modulates the immune condition and inflammatory response of European seabass. Fish. Shellfish Immunol. 2020, 106, 451-463. [CrossRef]

147. Uzzan, M.; Soudan, D.; Peoc'h, K.; Weiss, E.; Corcos, O.; Treton, X. Patients with COVID-19 present with low plasma citrulline concentrations that associate with systemic inflammation and gastrointestinal symptoms. Dig. Liver Dis. 2020, 52, $1104-1105$. [CrossRef]

148. Boonlaos, A.; Wechsirisan, W.; Chaibuth, P.; Chupia, V.; Chotinun, S.; Chuammitri, P. Quercetin enhances and modulates the fungal killing efficacy of chicken heterophils through immunological recognition, effector functions, and resolution. Comp. Immunol. Microbiol. Infect. Dis. 2020, 74, 101582. [CrossRef]

149. Yang, J.X.; Maria, T.C.; Zhou, B.; Xiao, F.L.; Wang, M.; Mao, Y.J.; Li, Y. Quercetin improves immune function in Arbor Acre broilers through activation of NF-kappaB signaling pathway. Poult. Sci. 2020, 99, 906-913. [CrossRef] 
150. Wan, M.L.Y.; Co, V.A.; El-Nezami, H. Dietary polyphenol impact on gut health and microbiota. Crit. Rev. Food Sci. Nutr. 2021, 61, 690-711. [CrossRef]

151. Wu, M.; Luo, Q.; Nie, R.; Yang, X.; Tang, Z.; Chen, H. Potential implications of polyphenols on aging considering oxidative stress, inflammation, autophagy, and gut microbiota. Crit. Rev. Food Sci. Nutr. 2021, 61, 2175-2193. [CrossRef]

152. Ju, S.; Ge, Y.; Li, P.; Tian, X.; Wang, H.; Zheng, X.; Ju, S. Dietary quercetin ameliorates experimental colitis in mouse by remodeling the function of colonic macrophages via a heme oxygenase-1-dependent pathway. Cell Cycle 2018, 17, 53-63. [CrossRef]

153. González, R.; Ballester, I.; López-Posadas, R.; Suárez, M.D.; Zarzuelo, A.; Martínez-Augustin, O.; Medina, F.S.D. Effects of Flavonoids and other Polyphenols on Inflammation. Crit. Rev. Food Sci. Nutr. 2011, 51, 331-362. [CrossRef]

154. Habtemariam, S.; Belai, A. Natural Therapies of the Inflammatory Bowel Disease: The Case of Rutin and its Aglycone, Quercetin. Mini Rev. Med. Chem. 2018, 18, 234-243. [CrossRef]

155. McCafferty, D.M. Peroxynitrite and inflammatory bowel disease. Gut 2000, 46, 436. [CrossRef]

156. Cross, R.K.; Wilson, K.T. Nitric oxide in inflammatory bowel disease. Inflamm. Bowel Dis. 2003, 9, 179-189. [CrossRef]

157. Kolios, G.; Valatas, V.; Ward, S.G. Nitric oxide in inflammatory bowel disease: A universal messenger in an unsolved puzzle. Immunology 2004, 113, 427-437. [CrossRef]

158. Stettner, N.; Rosen, C.; Bernshtein, B.; Gur-Cohen, S.; Frug, J.; Silberman, A.; Sarver, A.; Carmel-Neidermann, N.N.; Eilam, R.; Biton, I.; et al. Induction of nitric-oxide metabolism in enterocytes alleviates colitis and inflammation-associated colon cancer. Cell Rep. 2018, 23, 1962-1976. [CrossRef]

159. Luiking, Y.C.; Engelen, M.P.; Deutz, N.E. Regulation of nitric oxide production in health and disease. Curr. Opin. Clin. Nutr. Metab. Care 2010, 13, 97-104. [CrossRef]

160. Uyanga, V.A.; Wang, M.; Tong, T.; Zhao, J.; Wang, X.; Jiao, H.; Onagbesan, O.M.; Lin, H. L-citrulline influences the body temperature, heat shock response and nitric oxide regeneration of broilers under thermoneutral and heat stress condition. Front. Physiol. 2021, 12, 671691. [CrossRef]

161. Donald, J.A. Subchapter 103A: Nitric oxide in Handbook of Hormones: Comparative Endocrinology for Basic and Clinical Research; Takei, Y., Ando, H., Tsutsui, K., Eds.; Academic Press: Cambridge, MA, USA, 2016; pp. 603-605. [CrossRef]

162. Romero, M.; Jiménez, R.; Sánchez, M.; López-Sepúlveda, R.; Zarzuelo, M.J.; O’Valle, F.; Zarzuelo, A.; Pérez-Vizcaíno, F.; Duarte, J. Quercetin inhibits vascular superoxide production induced by endothelin-1: Role of NADPH oxidase, uncoupled eNOS and PKC. Atherosclerosis 2009, 202, 58-67. [CrossRef]

163. Loke, W.M.; Hodgson, J.M.; Proudfoot, J.M.; McKinley, A.J.; Puddey, I.B.; Croft, K.D. Pure dietary flavonoids quercetin and (-)-epicatechin augment nitric oxide products and reduce endothelin-1 acutely in healthy men. Am. J. Clin. Nutr. 2008, 88, 1018-1025. [CrossRef]

164. Zhang, Y.-M.; Zhang, Z.-Y.; Wang, R.-X. Protective mechanisms of quercetin against myocardial ischemia reperfusion injury. Front. Physiol. 2020, 11, 956. [CrossRef]

165. Ozu, O.Y.; Ertug, P.U.; Karabulut, E.; Kumcu, E.K.; Singirik, E.; Secilmis, M.A. Dose-dependent differential mechanism of quercetin-induced vasodilatations in isolated perfused rat mesenteric vascular bed. Int. J. Pharmacol. 2016, 12, 379-386. [CrossRef]

166. Deng, Q.; Li, X.X.; Fang, Y.; Chen, X.; Xue, J. Therapeutic potential of quercetin as an antiatherosclerotic agent in atherosclerotic cardiovascular disease: A review. Evid.-Based Complement. Altern. Med. 2020, 2020, 1-12. [CrossRef]

167. Martins-Perles, J.V.C.; Bossolani, G.D.P.; Zignani, I.; de Souza, S.R.G.; Frez, F.C.V.; de Souza Melo, C.G.; Barili, E.; de Souza Neto, F.P.; Guarnier, F.A.; Armani, A.L.C.; et al. Quercetin increases bioavailability of nitric oxide in the jejunum of euglycemic and diabetic rats and induces neuronal plasticity in the myenteric plexus. Auton. Neurosci. 2020, 227, 102675. [CrossRef] [PubMed]

168. Faddah, L.M.; Baky, N.A.A.; Mohamed, A.M.; Al-Rasheed, N.M.; Al-Rasheed, N.M. Protective effect of quercetin and/or l-arginine against nano-zinc oxide-induced cardiotoxicity in rats. J. Nanopart. Res. 2013, 15, 1520. [CrossRef]

169. Baky, N.A.A.; Faddah, L.M.; Al-Rasheed, N.M.; Al-Rasheed, N.M.; Shebali, W. Role of quercetin and l-arginine in alleviating zinc oxide nanoparticle hepatotoxicity in rats. Chiang Mai J. Sci. 2013, 40, 577-592.

170. Abdelhalim, M.A.K.; Moussa, S.A.A.; Qaid, H.A.Y. The protective role of quercetin and arginine on gold nanoparticles induced hepatotoxicity in rats. Int. J. Nanomed. 2018, 13, 2821-2825. [CrossRef]

171. Bhattacharyya, A.; Chattopadhyay, R.; Mitra, S.; Crowe, S.E. Oxidative stress: An essential factor in the pathogenesis of gastrointestinal mucosal diseases. Physiol. Rev. 2014, 94, 329-354. [CrossRef]

172. Coles, K.E. Investigation into the Antioxidant Capacity of L-Arginine and L-Citrulline in Relation to Their Vascular Protective Properties; Cardiff University: Cardiff, UK, 2007.

173. Salama, Y.A.; El-Karef, A.; El Gayyar, A.M.; Abdel-Rahman, N. Beyond its antioxidant properties: Quercetin targets multiple signalling pathways in hepatocellular carcinoma in rats. Life Sci. 2019, 236, 116933. [CrossRef]

174. Naseer, Z.; Ahmad, E.; Sahiner, H.S.; Epikmen, E.T.; Fiaz, M.; Yousuf, M.R.; Khan, S.A.; Serin, I.; Ceylan, A.; Aksoy, M. Dietary quercetin maintains the semen quality in rabbits under summer heat stress. Theriogenology 2018, 122, 88-93. [CrossRef]

175. Miyamoto, N.; Izumi, H.; Miyamoto, R.; Kondo, H.; Tawara, A.; Sasaguri, Y.; Kohno, K. Quercetin induces the expression of peroxiredoxins 3 and 5 via the nrf2/nrf1 transcription pathway. Investig. Ophthalmol. Vis. Sci. 2010, 52, 1055-1063. [CrossRef]

176. Luca, S.V.; Macovei, I.; Bujor, A.; Miron, A.; Skalicka-Woźniak, K.; Aprotosoaie, A.C.; Trifan, A. Bioactivity of dietary polyphenols: The role of metabolites. Crit. Rev. Food Sci. Nutr. 2020, 60, 626-659. [CrossRef] 
177. Akbarian, A.; Michiels, J.; Degroote, J.; Majdeddin, M.; Golian, A.; De Smet, S. Association between heat stress and oxidative stress in poultry; mitochondrial dysfunction and dietary interventions with phytochemicals. J. Anim. Sci. Biotechnol. $2016,7,37$. [CrossRef]

178. Chen, S.-H.; Lin, M.-T.; Chang, C.-P. Ischemic and oxidative damage to the hypothalamus may be responsible for heat stroke. Curr. Neuropharmacol. 2013, 11, 129-140. [CrossRef]

179. Lin, H.; Decuypere, E.; Buyse, J. Acute heat stress induces oxidative stress in broiler chickens. Comp. Biochem. Physiol. Part A Mol. Integr. Physiol. 2006, 144, 11-17. [CrossRef]

180. Quinteiro-Filho, W.M.; Ribeiro, A.; Ferraz-de-Paula, V.; Pinheiro, M.L.; Sakai, M.; Sa, L.R.; Ferreira, A.J.; PalermoNeto, J. Heat stress impairs performance parameters, induces intestinal injury, and decreases macrophage activity in broiler chickens. Poult. Sci. 2010, 89, 1905-1914. [CrossRef]

181. Chapman, J.C.; Liu, Y.; Zhu, L.; Rhoads, J.M. Arginine and citrulline protect intestinal cell monolayer tight junctions from hypoxia-induced injury in piglets. Pediatr. Res. 2012, 72, 576-582. [CrossRef]

182. Rhoads, J.M.; Chen, W.; Gookin, J.; Wu, G.Y.; Fu, Q.; Blikslager, A.T.; Rippe, R.A.; Argenzio, R.A.; Cance, W.G.; Weaver, E.M.; et al. Arginine stimulates intestinal cell migration through a focal adhesion kinase dependent mechanism. Gut 2004, 53, 514-522. [CrossRef]

183. Noiri, E.; Peresleni, T.; Srivastava, N.; Weber, P.; Bahou, W.F.; Peunova, N.; Goligorsky, M.S. Nitric oxide is necessary for a switch from stationary to locomoting phenotype in epithelial cells. Am. J. Physiol. 1996, 270, C794-C802. [CrossRef]

184. Gookin, J.L.; Rhoads, J.M.; Argenzio, R.A. Inducible nitric oxide synthase mediates early epithelial repair of porcine ileum. Am. J. Physiol. Gastrointest. Liver Physiol. 2002, 283, G157-G168. [CrossRef]

185. Lee, S.I.; Kang, K.S. Function of capric acid in cyclophosphamide-induced intestinal inflammation, oxidative stress, and barrier function in pigs. Sci. Rep. 2017, 7, 16530. [CrossRef]

186. Cai, X.; Chen, X.; Wang, X.; Xu, C.; Guo, Q.; Zhu, L.; Zhu, S.; Xu, J. Pre-protective effect of lipoic acid on injury induced by $\mathrm{H}_{2} \mathrm{O}_{2}$ in IPEC-J2 cells. Mol. Cell Biochem. 2013, 378, 73-81. [CrossRef]

187. Cai, X.; Wang, J.; Chen, X.; Guo, Q.; Zhu, L.; Xu, J. The Research Progress in Intestinal Epithelial Oxidative Stress Cell Model. Acta Vet. Zoo Sin. 2014, 45, 337-346.

188. Farkas, O.; Mátis, G.; Pászti-Gere, E.; Palócz, O.; Kulcsár, A.; Petrilla, J.; Csikó, G.; Neogrády, Z.; Gálfi, P. Effects of Lactobacillus plantarum 2142 and sodium n-butyrate in lipopolysaccharide-triggered inflammation: Comparison of a porcine intestinal epithelial cell line and primary hepatocyte monocultures with a porcine enterohepatic co-culture system. J. Anim. Sci 2014, 92, 3835-3845. [CrossRef]

189. Manjeet, K.R.; Ghosh, B. Quercetin inhibits LPS-induced nitric oxide and tumor necrosis factor-alpha production in murine macrophages. Int. J. Immunopharmocol. 1999, 21, 435-443.

190. Chirumbolo, S. The role of quercetin, flavonols and flavones in modulating inflammatory cell function. Inflamm. Allergy Drug Targets 2010, 9, 263-285. [CrossRef]

191. Chen, Z.; Yuan, Q.; Xu, G.; Chen, H.; Lei, H.; Su, J. Effects of quercetin on proliferation and $\mathrm{h}_{2} \mathrm{O}_{2}$-induced apoptosis of intestinal porcine enterocyte cells. Molecules 2018, 23, 2012. [CrossRef]

192. Penissi, A.B.; Rudolph, M.I.; Piezzi, R.S. Role of mast cells in gastrointestinal mucosal defense. Biocell 2003, 27, 163-172. [CrossRef]

193. Wang, X.; Zhang, C.; Zheng, M.; Gao, F.; Zhang, J.; Liu, F. Metabolomics analysis of l-arginine induced gastrointestinal motility disorder in rats using uplc-ms after magnolol treatment. Front. Pharmacol. 2019, 10, 183. [CrossRef]

194. Saccon, T.D.; Nagpal, R.; Yadav, H.; Cavalcante, M.B.; Nunes, A.D.D.C.; Schneider, A.; Gesing, A.; Hughes, B.; Yousefzadeh, M.; Tchkonia, T. Senolytic combination of dasatinib and quercetin alleviates intestinal senescence and inflammation and modulates the gut microbiome in aged mice. J. Gerontol. Ser. A Boil. Sci. Med Sci. 2021, 76, 1895-1905. [CrossRef]

195. Ghimire, S.; Wongkuna, S.; Sankaranarayanan, R.; Ryan, E.P.; Bhat, G.J.; Scaria, J. Rice bran and quercetin produce a positive synergistic effect on human gut microbiota, elevate the level of propionate, and reduce the population of enterobacteriaceae family when determined using a bioreactor model. bioRxiv 2020. [CrossRef]

196. Vazquez Prieto, M.A.; Bettaieb, A.; Rodriguez Lanzi, C.; Soto, V.C.; Perdicaro, D.J.; Galmarini, C.R.; Haj, F.G.; Miatello, R.M.; Oteiza, P.I. Catechin and quercetin attenuate adipose inflammation in fructose-fed rats and 3T3-L1 adipocytes. Mol. Nutr. Food Res. 2015, 59, 622-633. [CrossRef] [PubMed]

197. Amevor, F.K.; Cui, Z.; Du, X.; Ning, Z.; Shu, G.; Jin, N.; Deng, X.; Tian, Y.; Zhang, Z.; Kang, X.; et al. Combination of quercetin and vitamin $\mathrm{E}$ supplementation promotes yolk precursor synthesis and follicle development in aging breeder hens via liver-blood-ovary signal axis. Animals 2021, 11, 1915. [CrossRef] [PubMed]

198. Amevor, F.K.; Cui, Z.; Ning, Z.; Du, X.; Jin, N.; Shu, G.; Deng, X.; Zhu, Q.; Tian, Y.; Li, D.; et al. Synergistic effects of quercetin and vitamin $E$ on egg production, egg quality, and immunity in aging breeder hens. Poult. Sci. 2021, 101481. [CrossRef]

199. Shen, P.; Lin, W.; Deng, X.; Ba, X.; Han, L.; Chen, Z.; Qin, K.; Huang, Y.; Tu, S. Potential implications of quercetin in autoimmune diseases. Front. Immunol. 2012, 12, 689044. [CrossRef] [PubMed] 